Portland State University

PDXScholar

7-15-1977

\title{
The Use of Discrediting Labels in the Maintenance of Socially Constructed Reality
}

Nathan Church

Portland State University

Follow this and additional works at: https://pdxscholar.library.pdx.edu/open_access_etds

Part of the Mental Disorders Commons, Social Psychology and Interaction Commons, and the Theory, Knowledge and Science Commons

Let us know how access to this document benefits you.

\section{Recommended Citation}

Church, Nathan, "The Use of Discrediting Labels in the Maintenance of Socially Constructed Reality" (1977). Dissertations and Theses. Paper 2515.

https://doi.org/10.15760/etd.2512

This Thesis is brought to you for free and open access. It has been accepted for inclusion in Dissertations and Theses by an authorized administrator of PDXScholar. Please contact us if we can make this document more accessible: pdxscholar@pdx.edu. 
AN ABSTRACT OF THE THESIS OF Nathan Church for the Master of Science in Sociology presented July 15, 1977.

Title: The Use of Discrediting Labels in the Maintenance of Socially Constructed Reality.

APPROVED BY MEMBERS OF THE THESIS COMMITTEE:

Charles D. Bolton, Chairperson

Theo J.Majka"

Juan F. Longres

Over the past two decades an increasing number of theorists and practitioners have called for a thorough rethinking of the underlying assumptions of the concept of mental illness and the traditional psychiatric modes of responding to mental disorders. The work of this group of writers has come to be referred to as the "antipsychiatry" literature. The insights of this perspective center largely about a rejection of those theories and methods of treatment that are based upon the medical model. Many writers point to the use 
of traditional psychiatric practice as an oppressive instrument of social control. While much of this perspective is directed toward the analysis of specifically sociological

factors there have been few attempts by sociologists to provide focus for the claims that have been made.

This paper proposes a synthetic sociological framework with the intention of providing sociological focus for the otherwise disparate insights found within this literature. A general model is constructed by incorporating aspects of the labeling perspective, the sociology of knowledge, and Marxian analysis. The model provides the analytical tools for investigation of the manner in which "mental illness" as a concept, and the phenemenon which it allegedly describes, are rooted in the nature of everyday life. The framework that is developed places particular emphasis upon the political dimensions of everyday life. This dimension is especially useful in explicating the role of labeling as a device to discredit the claims of people as they attempt to identify the oppressive aspects of their social environment. The nature of socialization within Western culture is analyzed in terms of the various factors which are instrumental in the mystification of consciousness and its relationship to "mental illness."

The observation is made that the majority of the claims that are proffered by the "antipsychiatrists" are devoid of a firm empirical foundation in that they rely primarily upon 
findings from case studies and a series of loose inferences. An attempt is made to overcome this problem by mapping out the empirical points of departure for the model by developing a set of testable propositions and corollaries. It is concluded that a radical sociology of knowledge framework does provide a useful method of conceptualizing the "antipsychiatry" literature from a sociological perspective. The validity of the claims themselves, however, must wait until much more of the empirical evidence is in. It is pointed out that extreme caution be taken to avoid contentions to the effect that all mental disorders can be fruitfully analyzed by this framework or that capitalism per se causes mental disorder.

Suggestions are made as to the likelihood that some diagnostic categories, more than others, may be subject to analysis by this model. It is implied that further research into the role of biopsychological factors will undoubtedly show the interactive effects of such factors with defective socialization and oppressive social relationships. 
THE USE OF DISCREDITING LABELS IN THE MAINTENANCE

OF SOCIALLY CONSTRUCTED REALITY.

by

NATHAN CHURCH

A thesis submitted in partial fulfillment of the requirements for the degree of

MASTER OF SCIENCE

in

SOCIOLOGY

Portland State University

1977 
TO THE OFFICE OF GRADUATE STUDIES AND RESEARCH:

The members of the Committee approve the thesis of Nathan Church presented July 15, 1977.

Charles D. Bolton, Chairperson

Theo J. Majka

Juan Longres

APPROVED :

Cnarles D. Bolton, Head, Department of Sociology

Stanley E. Rauch, Dean of Graduate Studies and Research 


\section{ACKNOWLEDGMENTS}

It would be impossible to pay all of the "dues" that I owe for the help, instruction, and encouragement that went into the completion of this thesis. Working within very rigid time constraints I have taxed the endurance of virtually everyone involved. There have been many who shared intellectually and emotionally in this task. Those who have been instrumental in whatever scholarly components can be found within the text I want to acknowledge while fully accepting responsibility for the various shortcomings.

First, I would like to express very deep gratitude to my committee as a whole. They have allowed me the unique opportunity to use this experience to effect what I perceive to be the outstanding objective of this stage of graduate education; that is, the grasping of the broad theoretical issues involved in any subject area as a prelude to one's own research efforts. I am more than mildly concerned with the quantity of disjointed and superficial research that so often emerges at this level of training which does so little to expand social scientific understanding. The committee members, often pushed to the very limits of tolerance and understanding, have been more than accommodating in this regard for this thesis reflects my own perceptions to which they did not necessarily agree. 
First, I must thank Professor Bolton for the many hours of instruction and discussion through which he imparted to me an enduring concern for the oft forgotten role of the human individual in sociological analysis. His extreme patience in hearing out my own observations and formulations, so often ridden with incompleteness and incoherence, has been commendable. To Professor Majka goes my gratitude for the very amicable manner in which he has introduced me to radical sociological analysis. The time and effort that he has expended in response to my micro-level concerns are much appreciated. Professor Longres was very helpful in providing focus and clarity to my ramblings. The fact that he shares some of my sociopsychological concerns in the field of deviance has provided a crucial source of social support for some of the concepts and perceptions that I have been grappling with for some time.

Space does not permit me to acknowledge all of the graduate students, students in my own classes, and associates who have taken the time and interest to respond to the conceptual framework that is outlined in this paper. These exchanges have been enlightening and in many ways have been instrumental in the resulting conceptual framework.

I must in a very special way acknowledge the undaunted and loyal source of support and assistance that I have found in my wife, Debbie, throughout this entire endeavor. Somehow she has handled the responsibility of two children at a time 
V

when their father was often elsewhere and still managed to type all of the drafts of this paper. In a very real sense this paper would not have been possible without her help and emotional support. Her parents often provided encouragement and assistance to us both. Too many friends to mention here helped us along the way, often watching our children for us and always offering their support. 
TABLE OF CONTENTS

PAGE

ACKNOWLEDGMENTS . . . . . . . . . . . . . . . . iii CHAPTER

I INTRODUCTION . . . . . . . . . . . 1

Terminology and Theoretical Background . . 2

A Brief Note on Marxian Analysis and

Insanity . . . . . . . . . . 7

II A RADICAL SOCIOLOGY OF KNOWLEDGE . . . . 10

III THE SOCIAL CONSTRUCTIONS OF MENTAL ILLNESS • 25

The Construction of a Myth . . . . . 25

The False Scientism of Psychiatry . . . 33

Responses of Oppression to Calls for

Help............ . 4l 4

IV THE POLITICS OF EVERYDAY LIFE . . . . . . 52

The Politics of the Family . . . . . . 54

The Politics of the School . . . . . 65

The Politics of the Workplace . . . . 68

V A RADICAL MODEL FOR INTERPRETING SOCIO-

PSYCHOLOGICAL PROBLEMS IN LIVING • • . 73

VI CONCLUSIONS . . . . . . . . . 97

REFERENCES CITED ................ 103 
CHAPTER I

INTRODUCTION

Over the past two decades there has been a growing recognition of the need to rethink modern analysis of the phenomenon we commonly call mental illness. Although the number of theorists and practitioners that have written in this mode has grown steadily and their works have identified collectively as the "antipsychiatry movement" there is little evidence of serious attempts to systematize this approach sociologically. In fact there have only been a few attempts to bring exemplary writings together in book form. Although all of the writers make reference to the role of social structural, institutional, and other specifically sociological factors in shaping perspectives on the topic they move little beyond debunking the predominant use of the medical model in response to insanity. What this paper will attempt to do is to offer a sociological framework that incorporates the otherwise somewhat disparate insights found in the "antipsychiatry" literature. Our thesis for this effort will be to the effect that the "antipsychiatry" literature can be reconceptualized within a radical sociology of knowledge framework yielding a more coherent and fruitful analysis of the phenomenon of insanity.

There have been few sociological attempts to conceptu- 
alize the issues of insanity that have been raised in the "antipsychiatry" literature. This paper attempts to provide a sociological focus for these issues through a radical formulation of the sociology of knowledge. Being such an exploratory endeavor the paper will surely raise more questions than it will answer; nevertheless it is hoped that it will result in at least the skeleton of a sociological accounting of insanity that is superior to both the medical model and the insightful but theoretically incoherent "antipsychiatry" literature. One has to feel a bit uneasy about trekking through largely uncharted theoretical territory; regardless of what is offered here, a "final" statement at this exploratory stage will always be ipso facto an incomplete statement that will invariably be subject to a myriad of logical attacks and greatly in need of futher clarification. The reader is advised to view this paper as an attempt to formulate the beginnings of a different sociological approach to insanity. To force this paper into a logically refined and complete form denies its very purpose and nature as an exploratory, hypothetical, and tentative investigation.

\section{TERMINOLOGY AND THEORETICAL BACKGROUND}

The works of Thomas Szasz, appearing first in the mid-fifties, chronicle the emergence of a perspective on madness not in keeping with the traditional use of the med- 
ical model. Szasz has written most extensively on the subject, and his book The Myth of Mental Illness (1974) is a good synopsis of his approach although it is exemplified here with reference almost exclusively to hysteria. The next group of works in this general tradition is from R.D. Laing appearing first in 1960 (the Divided Self). The works of these two psychiatrists along with the sociologist Erving Goffman (Asylums, 1961) were virtually the only major examples of a nascent "antimedical-model" stance on insanity until quite recently. Recent efforts to collect the emerging writings and research formulated in this vein include three books, The Radical Therapist (1971) edited by Jerome Angel, Radical Psychology (1973) edited by Phil Brown, ${ }^{*}$ and Labeling Madness (1975a) edited by Thomas Scheff, and the emergence of two journals; Rough Times (formerly The Radical Therapist) and the Journal of Radical Therapy. While Scheff's book attempts to cast this general approach within the labeling perspective, the other recent sources do little more than imply the possibility of interpreting the "antipsychiatry" literature from a general Marxian or radical perspective. These two general approaches to systematizing the insights from the "antipsychiatry movement" are ridden with both incoherence and contradiction.

*Brown's text is apparently the first to identify this approach to insanity under the rubric of "antipsychiatry." see chapter two. 
Incoherence is exhibited by both strategies. First, the labeling perspective itself has suffered extensive criticism for its own lack of theoretical clarity and coherence; * Scheff offers no major improvements in this book. Furthermore he fails to include any of the works of Laing, Szasz, or Goffman, thus falling far short of dealing with the full range of concerns that are characteristic of the "antipsychiatry" literature. As Walter Gove (1975a:61) has observed, the labeling theorists of mental illness do not forward a general explanation of the phenomenon itself. Although Scheff (1975:90-92) does suggest the notion that mental disorder is related to the repression of emotion he comes far short of offering a general explanatory framework. The radicals are also guilty of a lack of coherence in their approach insofar as they make reference to a Marxist psychology as if it were something already well formulated in the writings of Marx, which is simply not the case, as is pointed out by Adam Schaff (1970:40-2), Peter Berger (1969: ix), Richard Lichtman (1975:58), and Richard Ropers (1973: 42).

The contradictory characteristics of the radical approach can be found in the efforts to overcome the problem just mentioned by developing a Marxist psychology. The very

* See the discussion in Don Gibbons and Joseph Jones (1975:124-134) which is a concise accounting of the major criticisms of the labeling perspective. 
use of the wording a "Marxist psychology," represents a contradiction in terms. Marx, in the few places that he grapples with the issue of the human individual, deviates markedly from a psychologistic perspective as it is implied in the terms "a Marxist psychology." For example, he had nothing but sharp criticism of Feuerbach for postulating "an abstract - isolated - human individual" (emphasis in the original). In contradistinction Marx contended that "the essence of man is not an abstraction inherent in each particular individual. The real nature of man is the totality of social relations" (1964:68). Thus, while it might make sense to talk of a Marxist social psychology (or sociopsychology), to speak of a Marxist psychology goes against the grain of a truly Marxist perspective.

The central emphasis of the radical "antipsychiatrists" is to focus attention on social relationships in modern capitalism as the true locus of what have traditionally been viewed as personal psychic disorders. Yet they persist in their efforts to develop a psychology which tends toward movement of the causal nexus in the direction of the individual. This is undoubtedly an inadvertent consequence of the training and background of the radicals which is almost exclusively psychiatry and psychology. It remains a contradiction, however, and reflects a serious problem in their work. The need to overcome this deficiency is pointed out by Angel (1971:xvi) in arguing that the therapist , 
"expert as he may be at analyzing interpersonal forces, he is often ignorant about forces controlling the larger society in which he lives. This must be exposed and clarified." Michael Glenn (1971:xi) identifies a serious consequence of an individualistic approach in therapy in that "emphasis on the individual cools people out . . by turning their focus from society . . to their own 'hang-ups.' " Yet neither writer moves beyond radical psychology as a framework from which to answer the problems they find in traditional psychology.

This contradiction has been an historical feature of Marxism since its rebirth in the 1950's and '60's in the universities. Since that time the writings of Erich Fromm, Reuben Osborne, Wilhelm Reich, and Herbert Marcuse have largely served as the modern Marxist psychology. Keith Brooks (1973:322-328) contends that the movement toward a Freudian perspective was more a reaction to cold sterile behaviorism than a logical and coherent effort to develop a Marxian microview of social relations. Although Brooks also fails to see much beyond a Marxist psychology himself he does offer the most complete refutation of the type of psychology found in Freudianism. * The following passage captures his view of Freud's psychology:

*On this point, see also Richard Ropers (1973:43) and Peter Berger and Thomas Luckmann (1967:194). 
Freudianism, as a microview that considers the "truth" of human beings to reside outside of their social relations, does not even understand individuals ... the only contribution freud made was in providing the basic concepts to be used in the mystification and obfuscation of people's everyday

lives. Freudianism is part of the problem. (Brooks, 1973:322) (emphasis in the original)

What Brooks calls for is a theoretical framework that offers "a definition of the individual as a social being, as a being-in-the-world" (1973:333). What follows in this paper can be viewed largely as an attempt to wrestle with this question.

What we hope to discover here is a theoretical strategy that will incorporate both the labeling perspective and a radical perspective on the issue of insanity. The belief is that this can be accomplished through a radical interpretation of the sociology of knowledge. In the next chapter we will deal explicitly with that radical sociology of knowledge framework. In Chapter III a brief analysis utilizing a radical sociology of knowledge will be employed in regards to psychiatry and the concept of "mental illness." Chapter IV will focus attention on the politics of everday life and offers a radical interpretation of the processes involved. In Chapter $\mathrm{V}$ a series of testable propositions deriving from a radical sociology of knowledge framework is presented. Chapter VI will try to draw some conclusions on the basis of our sociological excursus into insanity.

A BRIEF NOTE ON MARXIAN ANALYSIS AND INSANITY 
As we have implied already, Marxian analysis of sociopsychological phenomena is poorly developed and this paper is suggestive of a possible strategy to overcome this deficiency. In this endeavor several issues emerge which would threaten the clarity of the analysis that follows. Thus, for purposes of clarification we need to offer a very brief discussion of some of the factors involved in a Marxist analysis of insanity. Our analysis will almost exclusively limit attention to insanity as it occurs in Western culture under the reign of capitalism. If the argument presented here were to postulate a simplistic unilinear causal argument that capitalism-causes-insanity, the facts would immediately invalidate our contentions. Obviously this is not the case and yet for some reason critics of Marxian analysis tend to force it into these kinds of formulations (undoubtedly some Marxian arguments are sufficiently rhetorical to warrant this criticism); Marxist analysis should not be construed so as to minimize the problems within those forms of political economy which both precede and follow capitalism. A truly Marxist perspective simply focuses upon the dialectical relationship between the base, substructure, and superstructure in any society. Our analysis does not mean to imply that insanity did not exist before capitalism or that it will disappear with its demise. Instead, we simply contend that the forms of oppression will always differ qualitatively within different political economies. How 
much they differ quantitatively is an empirical question. It would seem to follow, however, that smaller differentials in power would yield a smaller potential for oppression. We still await these future societal forms of more equitable distributions of power and privilege. When they manifest themselves then, and only then, can we subject this question to empirical test. At present, however, we can point to the way in which control of the means of material production in capitalist society also effects control of the means of intellectual production. We can look to the factors upon which power is based in this society and the way in which that power is used to maintain itself politically from "macrolevel" to "microlevel" contexts.

The causal influence of oppression or coercion that is related to insanity in the following pages should not be interpreted as an explanation for all cases of insanity. We are merely suggesting the way in which some mental disorders might be a function of various oppressive social relationships or how that some mental deficiencies may be intensified by them. Conclusions as to the accuracy of this contention must be based upon research that follows from this line of causal reasoning. The general parameters of such investigations are outlined in Chapter $V$. 
CHAPTER II

\section{A RADICAL SOCIOLOGY OF KNOWLEDGE}

We can begin our effort to ford this theoretical river by stepping in at the point marked off by the sociology of knowledge framework as it has been generally expounded by Peter Berger and Thomas Luckmann (The Social Construction of Reality, 1967). What is envisioned here will not be an extraction or formulation of a separate theory on the question of deviance in that we will be directing attention away from the deviant(s). This strategy is not new as the labeling people advocate a similar procedure; yet in turn they wish to inspect the situational context and those persons and institutions that attach the label of deviance. What we shall see here is an attempt to focus attention away from deviants one step further toward an inspection of everyday life and the nature of social reality. In this way we can discuss deviance in the same context that we would use to deal with conformity. Within this approach, conformity is equivalent to sanity; that is, accepting the status quo as real and singular. Challenging the status quo, or insanity, evokes social control which itself, through labeling, serves to maintain or reify the contemporary conceptions of reality as natural facts which ipso facto exclude any alternative 
conceptions of reality not contained within the commonly shared symbols, signs, and meanings manifested in everyday language. Social control, at least in part, results in the attachment of a label to a challenger which discredits him or her and the alternative perception of reality that is presented. An investigation of these issues will necessitate discussion of processes of internalization within a general symbolic interactionist frame of reference which itself is intricately linked with the sociology of knowledge (at least in Berger and Luckmann's notion of such). The reader should be sensitive, however, that the central focus of this paper is an endeavor to extend a radical social perspective to microlevel social phenomena, uncovering the sociopsychological violence and oppression that characterizes much of everyday life and consciousness as it is manifested in the issues of insanity.

A question may arise at this point as to the advisability of incorporating bourgeois theory in a radical formulation of theory. One perspective in Marxist thought suggests that any bourgeois theory is inherently laden with class bias that invalidates any of its insights. A growing number of radicals have advocated just such a procedure, however, in response to some of the deficiencies in the Marxist perspective.* As is pointed out by Richard Lichtman

\footnotetext{
*For example see R.W.J. Dingwall (1975), Donald Hansen (1976), Richard Ropers (1973), and Mark Wardell (1975).
} 
(1975:58) radicals can benefit by studying the works of some bourgeois theorists.

But Marx left important issues unsolved; and time has added new ones. It is not enough for us to repeat Marx's formula. The dialectic of subjectivityobjectivity has not been fully grasped as yet, and we have much to learn about the is sue . . . from bourgeois writers like Mead (with his emphasis on the social origin of the self), [and] social interactionists like Seely, Blumer, Berger and Luckmann (sensitive to the intentionality and objectification of social rules)...

Coming from the other direction, we will take Berger and Luckmann seriously in their advocacy of a humanistic stance in sociology that would require "a systematic accounting of the dialectical relation between the structural realities and the human enterprise of constructing reality - in history" (1967:186). At the outset, at any rate, we are probably on safe ground to infuse radical insights into their work without distorting its fundamental intelligibility.

Another question that we need to explore is the manner in which we can discuss labeling perspective. Perhaps the easiest way to deal with this matter is to examine the role of labels in the maintenance of cultural themes. For our purposes we can view such themes as part of the superstructure which, according to Charles Bolton (p.17), can be seen as equivalent to what Berger and Luckmann call the symbolic universe. These cultural themes permeate the other "phenomenologically objectified products of the social process." The most significant of these products is language in that it provides for sharing and transmission of cultural themes 
or meaning and reality between groups, individuals, institutions, and generations. The particular aspect of language that is central to the immediate question is the role that it plays in social control. Thus, language provides for the transmission of cultural themes and also protects those themes in providing labels that discredit social actors that challenge their legitimacy. For example, Trent Schroyer (1975) contends that the dominant cultural theme in America is the "technocratic strategy in which politics and science are related integrally as the means for a more efficient and effective decision-making process" (p.19). According to Schroyer this grants a scientistic legitimation to the "manis-pawn-of-natural-necessity theme" that coerces us into a perception of the present form of our social world as inevitable when it really is a contrived device which serves as "a justification of the perpetuation of private power and privilege" (p.25). The reality of the barbarism that is engendered within such a society is unmasked by dissenters only to be denied by labeling such dissent as treason. This label discredits the challengers and the observations that they make. The dynamics of the process include the crediting labels or titles of these doing the labeling as is revealed in some observations made by Brooks (1973:349) about the label of paranoia.

Paranoia, like other Freudian concepts, has the primary effect of discrediting a person's Iife situation as the ground for behavior. The political purpose of this is .. obvious . . . 
such as when Bruno Bettleheim labeled people who were protesting the firing of Marlene Dixon from the University of Chicago as paranoids, or when Thomas Foran, who was the chief procecutor of the Chicago Eight said that all talk about political repression in this country was paranoia (!).

Given a political context the dynamics of discrediting labeling are fairly straightforward. The issues become somewhat more muddied when this process is analyzed within the context of the politics of everyday life (i.e. the politics of the family, shcool and workplace). A detailed analysis of the political features of everyday life in these contexts will be dealt with later; for now the focus will be directed to the general manner in which these are a reflection of the class struggle that characterizes the "macropolitical" sphere.

It can be argued, as Schroyer (1975:17) does, that domination in modern society "is broader than economic exploitation and alienation." For instance, one could easily agree that it would be ludicrous to postulate the direct operation of the class struggle in the politics of the family, but, to overlook its indirect effects would result in a serious shortcoming. One's perception of his or her family and its everyday operations is largely the result of the socialization one receives from schools, churches, and the media.* Class control of these sources of consciousness

* of course the family itself, as well as peers, are significant sources of influence for this perception, but these sources of influence are typically instrumental in aiding the transmission of cultural values and norms that 
production would effect a cruciad albeit indirect effect of the class struggle as Lichtman (1975:54) so lucidly describes.

Power over material production confers power over the production of consciousness. The ruling class exercises its power to distort consciousness through its control over the means of intellectual production - schools, churches, the daily press, etc. I think it is clear that this model fits the pattern of the base-superstructure, and locates the source of mystification in the control over the superstructure which the ruling class exercises as a consequence of its dominance over material wealth.

This explanation follows from Marx's (J967a:438) own contention that "the class having the means of material production has also control over the means of intellectual production." Lichtman's conception reveals a "dialectical relationship between base and superstructure, productive forces and relations of production, etc." (1975:56) an understanding of which is the only justifiable manner in which to break social reality down into these categories. For example, he states that the social relations of production cannot "be divorced from the remaining legal, moral, sexual, and religious institutions through which dominance and submission are internalized" (1975:57). In other words, the superstructure is both a consequence of the base as well as a source of its reinforcement and reification. It becomes, in the minds of people, a "natural" feature of the environment. Labels, symbols, language, cultural themes, in-

they receive themselves from schools, churches, and the media. 
stitutions, and so on interact dialectically in providing a Weltanschauung that reifies the base as both legitimate and singular. Inasmuch as language plays a crucial role in this interaction by virtue of being the essential mode of expression at all levels it would follow that themes of dominance and submission permeate the politics of everyday life as witnessed in the family, school, and workplace. We have already discussed the way in which labels are employed in traditional political contexts to discredit dissidents reacting to oppression and barbarism. The point here is that discrediting labeling also occurs in the context of the politics of everyday life to invalidate the claims of those who choose to identify its various oppressive dimensions.

A radical sociology of knowledge framework informs us as to both the dialectical and phenomenological aspects of this process. Berger and Stanley Pullberg (1965) take a large step in this direction in offering a "critique of consciousness" that incorporates two Marxian concepts: alienation and reification. In their analysis they separate the socially necessary processes - objectivation and objectification - from those extensions or extremes of these processes - alienation and reification. They argue that while social life requires objectivation (e.g. making tools or similar objects) and objectification (e.g. the "name" given to the tool which establishes distance between man and product) the processes of alienation and reification are "de 
facto characteristics of the human condition" (p.201). Alienation is the point in the phenomenological process at which the product becomes an alien facticity that is no longer recognizable as a product. Reification is the point in the process of alienation at which "the characteristic of thing-hood becomes the standard of objective reality" (p.200) (emphasis in original). These phenomenological processes occur within the framework of social structure which, according to Berger and Pullberg, is the result of the historical nature of objectivation. Berger and Pullberg describe the relationship between man and social structure as "a dialectical one. That is, social structure is produced by man and in turn produces him . . man produces himself as a social being through social structure" (p.202). In The Social construction of Reality Berger and Luckmann expatiate upon the phenomenological aspects of these insights but fail to extend any of the dialectical insights found in Berger and Pullberg's article, although they (i.e. Berger and Pullberg) imply the wisdom of developing a "critique of everyday life - . that can proceed in a phenomenological and a Marxian manner. . " (p.2ll). Although they describe social structure as "a coercive instrumentality" (p.202) their insights are not radical in that they choose to deal explictly with only the phenomenological taken-for-grantedness of the world as an a priori feature of social control while merely imply- 
ing its role in violent or oppressive social control.*

In Herbert Marcuse's (1964) analysis of modern society social control is described as being less blatant and observable and ever more mystified and coercive. The unwitting response of societal members as they participate in the reality that is defined by the controls does not deny that they (the controls) really exist but rather "it only testifies to the efficacy of the controls" (p.8). Marcuse's argument is that the controls are so effective that they "appear to be the very embodiment of Reason for the benefit of all social groups and interests - to such an extent that all contradiction seems irrational and all counteraction impossible" and therefore protest or "intellectual and emotional refusal 'to go along' appears neurotic and impotent" (p.9). Society thus is submerged in a "one-dimensional reality" that is sufficiently enshrouded in mystification so as to deny the possibility of its own negation. What happens to those who envision the ability to transcend the reality of the status quo - those who perceive that reality has more dimensions than are peddled hypnotically by "the makers of politics and their purveyors of mass information" (p.14)? According to Marcuse such dissenters are sufficiently diffused centrifugally by the reign of "objective" one-

*Violence as it is used here does not refer to physical violence per se but to what David Cooper (1973a:128) discusses as a "subtle, tortuous violence" that is often perpetrated by ostensibly "helpful" professionals. 
dimensional reality that they can be handled by psychiatrists and thereby be "cured" (p.71).

For now we can turn our attention to the analysis of labeling as a phenomenological process. A beginning point for this exercise is the discussion in Berger and Luckmann (1967:30-34) of typificatory schemes or the process of typification. They contend that social actors enter face-toface interactions with a set of typifications of the other person. These typifications are subject to modification as interaction progresses and one realizes that some or all typifications of the other are contradicted by incoming information. One may typify the other as grouchy or guff, for instance, only to find in an interactional episode of a matter of minutes that this person is not grouchy but in fact quite amiable. Berger and Luckmann discuss such interactive settings in such a way that we are left with the impression that both actors in a situation are equally empowered to alter the other's typifications. Obviously there are few situations in which both parties are equivalent in terms of their power to modify the other's typifications. This oversight effects a serious misrepresentation of many or most interactional settings. There are at least two ways in which the most powerful of two actors can with some degree of permanence attach a label or typification to the other. The first is exceeding subtle and imperceptable. While the weaker actor may speak to the more powerful or prestigious actor 
within an original mode of expression that assumes one typificatory scheme the latter may listen and then speak within a different mode. The subtlety of the latter's power will generally cause the former to shift to the mode of expression utilized by the latter thus being forced into the accompanying typifications. Thus, if a "patient" is complaining about the dynamics of family, work, or school, the psychiatrist may be listening and speaking in terms of mental disorder or neurosis. Inevitably the "patient" will soon be talking in these terms as well, thus molding him- or herself into the psychiatrist's typifications. The second strategy is more blatant and coercive. The more powerful actor may participate in the interaction by simply asserting a typification or label which forces the weaker actor into a "damned if I do - damned if I don't" situation. That is to say that the weaker actor has two choices: (1) to respond by denying the typification, in which case his or her continually frustrated denials eventually reach an emotional level that is identified by the more powerful actor as symptomatic of the typification; or, (2) to refuse to respond to the other's claims, in which case his or her silence is taken as an admission to the verity of the label.

Berger and Luckmann contend that there is heavier reliance on typifications "as they are removed from the 'here and now' of the face-to-face situation" (1967:33). This implies that face-to-face interaction is seldom, in the later 
stages, characterized by typifications or labels. Such a notion runs counter to the reality of many instances in society in which highly institutionalized role behavior creates the contingencies for the predominant use of labels, categories, diagnoses, typifications, and so forth. A police officer arresting a juvenile, for example, may often rely upon a typificatory scheme that has been formulated in relation to dealing with large numbers of juveniles over an extended period of time and passed on to new recruits by the older officers. In such cases the person is labeled as a particular type of person because the observed or suspected behavior is "characteristic" of that type. As Berger and Pullberg (1965:206) have observed, the behaviors in such situations "are perceived as standing separately from their performers." They contend that actors are often related to simply in terms of being embodiments of roles. In the initial stages of an episode, however, there exists a considerable degree of ambiguity or a variety of potential role ascriptions. Our police officer, for instance, may find a juvenile with a rock in his hand standing outside a school building where a window has been broken. While the question could be: "What explicit behavior has occurred?"; the question very often is: "What type of juvenile offender is this?" In other words the officer is likely to ascribe a role which would predispose the actor to a particular behavioral category. The implications of this distinction are significant 
inasmuch as the same situation could result in different role ascriptions yielding at least four definitions of the situation: (1) the window was already broken and the youth is about to break it out completely; (2) the youth accidentally broke the window while throwing at something else;

as a simple case of vandalism; or, (4) the youth was attempting to "break and enter." A variety of factors may affect the officer's eventual definition of the situation such as the type of language, clothing, and gesticulations that are exhibited by the youth. Kai Erikson (1967:11-12) describes this process as the operation of a screening device.

The screening device which sifts these telling details out of the person's over-all performance, then, is a very important instrument of social control. We know very little about the properties of this screen, but we do know that it takes many factors into account which are not directly related to the deviant act itself: it is sensitive to the suspect's social class, his past record as an offender, the amount of remorse he manages to convey, and many similiar concerns which take hold in the shifting moods of the community. This may not be so obvious when the screen is dealing with extreme forms of deviance like serious crimes, but in the day-by-day filtering processes which take place throughout the community this feature is easily observable. Some men who drink too much are called alcoholics and others are not, some men who act oddly are committed to hospitals and others are not, some men who have no visible means of support are hauled into court and others are not - and the difference between those who earn a deviant label and those who go their own way in peace depends almost entirley on the way in which the community sifts out and codes the many details of behavior to which it is witness.

The eventual definition effects a role ascription that fits the officer's typificatory scheme which, at least in 
part, has its roots in cultural themes as they are reflected in the community. "Thus, a working-class youth clad in leather jacket and jeans, employing "ghetto lingo" stands a good chance of being cast into a criminalistic role yielding the most severe behavioral category as a definition of the situation.

What occurs in such situations is a crystallization of roles and understandings that are resistant, in varying degrees, to modification. Once the typification, label, or role is ascribed, the original ambiguity of the situation is phenomenologically replaced by a concrete social construction or definition which is the basis for any further processes that may be involved. According to Edwin Shur (1973: 120-126) this original step is called stereotyping, which is followed by retrospective interpretation and negotiation. "Retrospective interpretation is the process by which once an individual is identified as deviant, he is seen in a totally 'new light.' " The phenomenological nature of this process is described by Harold Garfinkel (1956:421-22).

The work of the denunciation effects the recasting of the objective character of the perceived other: The other person becomes in the eyes of his condemners literally a different and new person. It is not that the new attributes are added to the old "nucleus." He is not changed, he is reconstituted ... . The new identity is the "basic reality." (emphasis

*See also Don Gibbons' (1976:38-46) discussion of these influencing factors in a treatment of "offender-police characteristics and police decisions" and "offender-police interaction" as they relate to juvenile delinquency. 
in the original)

Thus, the labeled person's past is reinterpreted within the parameters of the label. In cases such as alleged delinquency or "mental illness" the categories or diagnoses are so vague and ambiguous as to engender retrospective interpretation in sometimes very extreme or strained dimensions as we will soon observe.

Negotiation refers to the bargaining between the labeled person and the labelers regarding the terms of their relationship. Power is an important factor in all cases of bargaining, and the lopsided relationship between the psychiatrist and the patient is no exception. The patient is at an obvious disadvantage; even if he or she should exhibit behavior that objectively challenges or contradicts the psychiatrist's perception such an "experience will not contradict it," according to Judith willer (1971:19).

We will find the concepts of stereotyping (i.e. typifying or labeling), retrospective interpretation, and negotiation informative as we turn our attention to psychiatry and "mental illness." 


\section{CHAPTER III}

\section{THE SOCIAL CONSTRUCTIONS OF MENTAL ILLNESS}

So a sick society invented psychiatry to defend itself against the investigations of certain visionaries whose faculties of divination disturbed it.

ANTONIN ARTAUD*

\section{THE CONSTRUCTION OF A MYTH}

Humans show an amazing propensity thoughout history to accept any plausible explanation for complex phenomena rather than to admit that they don't have even a modicum of genuine understanding. These explanations are often extremely simplistic; the product of religious mysticism, generations of interwoven superstitions, or collections of common sense "insights." The problem with such formulations is that, though often far from being true, they do constitute knowledge within specific historical parameters and as such serve as the basis for action that reinforces that knowledge. That is to say that such knowledge of ten circumscribes the very actions that would eventuate in its demise or modification. Belief that the world was flat, for example, for a long period obviated those ocean voyages that eventually disproved it.

*An observatrion made by Artaud (1965:135) who spent fifteen years of his life in an asylum. 
Knowledge formulated in this way is highly resilient. An additional complicating factor of importance is that knowledge very often leads to institutional structures with various role positions characterized by power and privilege that have a vested interest in maintaining the contemporary perceptions and formulations of that knowledge. When change does occur it does so very slowly with its early proponents in danger of being riduculed, ostracized, or worse. The experiences of Galileo in astronomy and John Huss in theology bear witness to an enduring problem in knowledge.

Since New Testament times the Western world has produced a variety of plausible explanations for the phenomenon now generally referred to as mental illness. Although one can find definite improvements in this latest form of knowledge over previous ones, such as those previous beliefs which led to the "witch hunts" of Puritan New England, we will examine the ways in which "mental illness" as a social construction is devoid of the inherent skepticism that enables scientific perspectives to continually modify their tentative formulations of knowledge.

At some point in the history of insanity it was no longer tenable to conceptualize this phenomenon as individuals possessed by demons or spirits. Szasz (1974:17-31) points to Jean-Martin Charcot (1825-1893) as the father of a new response to insanity as a "mental disease." As a neurologist and neuropathologist, Charcot postulated from 
his post-mortem examinations of subjects afflicted with various organic disorders that all insane persons suffered from some other form of neurological defect and were thus also "il1." Charcot thus set psychiatry on the tracks as a form of medical science. Charcot accomplished this by his simple insistence that malingering (i.e. feining symptoms like those of organically impaired patients) was really an illness he called hysteria. Freud inadvertently reveals the unscientific manner in which this "discovery" was made - merely on the basis of Charcot's prestige.

He explained that the theory of organic nervous diseases was for the present fairly complete, and he began to turn his attention almost exclusively to hysteria... [which] had at this time come very much into discredit.. . The general opinion was that anything may happen in hysteria: hysterics found no credit whatsoever. First of all Charcot's work restored dignity to the subject; gradually the sneering attitude, which the hysteric could reckon on meeting when she told her story, was given up; she was no longer a malingerer, since charcot had thrown the whole weight of his authority on the side of the reality and objectivity of hysterical phenomena. (Freud, 1948:18-19) (emphasis added)

It is pointed out by Szasz (pp.28-29) that Charcot's demonstrations and explanations of hysteria were shown by Georges Guillain and others to be fakes. Seemingly Charcot could not admit that hysteria might have causes that were not internal, as his prestige in the matter derived from his role as a medical scientist; "this meant that he had to base his

* Goffman (1973:26-27) contends that the similarity between organic and functional psychoses largely accounts for the unreflective acceptance of the medical model in psychiatry. 
case about hysteria on the premise that it was an organic neurological illness. Otherwise, if hysteria and hypnosis were problems in human relations and psychology, why should anyone have taken Charcot's opinions as authoritative?" (Szasz, 1974:26). One could muse that Charcot had still provided an advancement for the insane by virtue of reifying their condition as illness which would accord them an "excused" social status for their behavior. In fact, however, the myth propagated by Charcot, Kraepelin, Breuer, Freud, and many more performs a disservice for the insane as Szasz (1974:24-25) succinctly explains:

It might seem, at first glance, that to advocate, and indeed insist, that an unhappy or troubled person is sick - and that he is sick in exactly the same sense and way in which a person suffering from cancer is sick - is humane and well-intentioned, as it aims to bestow upon such a person the dignity of suffering from a genuine illness over which he has no control. However, there is a hidden weight attached to this tactic which pulls the suffering person back into the same sort of disrepute from which this semantic and social reclassification was intended to rescue him. Indeed, labeling individuals displaying or disabled by problems in living as "mentally ill" has only impeded and retarded the recognition of the essentially moral and political nature of the phenomena to which psychiatrists address themselves.

It wasn't long after the insane asylum was introduced as a reform in this country, for example, before contentions regarding its oppressive potential for the insane, or those alleged to be insane, were vocalized. Acquiring the label of "mentally ill" and subsequent confinement to an asylum effects a dramatic curtailment of freedom and basic civil 
rights and therefore constitutes at least the potential for flagrant oppression. According to S. Kirson Weinberg (1968), as early as 1849 legal suits were being brought against individuals responsible for commitments.

While asylums were a decided improvement over previous practices, such as chaining insane persons to dungeon walls (Europe) or auctioning them off like chattel for hard labor (America), they did not represent a rational response to the state of psychiatric theory and treatment practices. As is pointed out by Szasz (1974:18), David Rothman (1971:xv-xvi), and Goffman (1973:28-30), asylums were the societal response to a social problem which could best be handled by warehousing the troublesome individuals in institutions where they would be "out of sight and out of mind." Often a person finds him- or herself committed to one of these institutions contrary to his or her own wishes. According to one set of statistics (Weinberg, 1971:183) over 45 percent of the admissions to mental hospitals are other than voluntary. Some like Szasz (1974:260-261) are primarily concerned with those subjected involuntarily to treatment and commitment but Seymour Halleck (1971), another psychiatrist, rejects this strategy. In a manner more fully sensitized to the political functions of the psychiatrist he depicts them as legitimators of the system of knowledge inherent in the status quo. Halleck (1971:36) observes, that while critics like Szasz, Laing, and others . . "have pointed out the repressive 
uses of involuntary psychiatry; they have not acknowledged that even when psychiatric treatment is voluntary it has profound political consequences." Psychiatrists argue to the contrary, however, contending that their actions are purely medical and therefore politically neutral. This contention is questionable in light of Halleck's insights into the nature of psychiatric intervention or treatment.

In dealing with the individual, the psychiatrist usually emphasizes that person's internal problems. Psychiatric treatment that focuses upon internal conflict encourages the patient and those who influence him to believe that his social environment is not contributing to his misery and that the environment is therefore adequate. So long as treatment does not encourage the patient to examine or to confront his environment and so long as treatment protects those who have adversely affected that patient from considering their own behavior, the net effect of treatment is to strengthen the status quo . . It is apparent that whatever the psychiatrist does, he will either encourage the patient to accept the existing distributions of power in his world or encourage the patient to change them .. . There is a strange and unfortunate tendency among psychiatrists to believe that professional activities designed to change the status quo are political and activities tending to strengthen the status quo are medical and neutral. This kind of thinking is illogical. By reinforcing the position of those who hold power, the psychiatrist is performing a political act whether he intends to or not. Once this fact is appreciated, the psychiatrist's search for political neutrality begins to appear illusory. (Halleck, 1971:35-36)

The picture of psychiatry presented here by Halleck portrays it as a mechanism to correct the failures of the socializing agencies such as the family, school, church, and workplace. Most, however, are successfully socialized to passively accept the oppressiveness of their environment. 
The observations on this point that have been made by Terry Kupers (1976) are instructive. In the social structures of capitalism Kuper's contends that Marx's (1967b:72) observation that human relations are subject to reification is still valid; that the ". . social relation between men ... assumes in their eyes, the fantastic form of a relation between things." The history of capitalism is the constant acceleration of social relationships to maximize efficiency and profits. The rationalization of productive forces has proceeded to the point where "the human qualities and idiosyncracies of the work appear increasingly as mere sources of error" (Georg Lucács, 1971:91). In this world people "feel like things, more the object than the subject of their lives" (Kupers, p.111). According to Kupers, such a society "is 'schizophrenogenic.' But common as it is, outright schizophrenia is not the plight of the entire population. Most people find a different way to live with reification" (p.117). This is accomplished in socialization.

In the course of "normal" socialization, moments arise where the child is encouraged to ignore or be numb to certain events and experiences. As he or she learns which events and experiences are not to be noticed the child is shaped into conventional consciousness. (Kupers, 1976:118)

Those that deviate from this mode of behavior are responded to by some of the social control agencies of society. These violations against conventional consciousness effect a class of deviations that fall outside of the more obvious forms of deviance. Most categories of deviance are clearly delineated 
- burglary, murder, embezzling, etc. - but some are not and fall under the type of deviance referred to as mental illness; a residual category, according to Scheff (1975b:7), which by its very. nature is vague and ambiguous. Ambiguity is an integral feature of "mental illness" as we will see in more detail in the next section of this chapter.

The extensive experience that Halleck relates of working with university students and in private practice with typical middle-class patients unmasks the general "cooling out" function of modern psychiatry. The dissident student experiencing extreme stress is encouraged to displace his attention to some less volatile and stress producing activity; end of dissidence. The middle-class wife suffering from the oppressiveness of a domineering husband is encouraged to develop other interests that will defuse her complaints of being unhappily married; "successful" termination of marital discord. In this manner psychiatry helps people to adjust to oppressive environments in the family, school, work, or politics. Those who don't adjust find themselves warehoused; the failures of both socialization and the remediation of psychiatry. According to Halleck (1971:28) psychiatric patients are usually responding to the oppressive influence of some other person, group, or institution although they may be partially or even totally unaware of the source of their troubles. Emphasis on internal factors will certainly exacerbate this problem of awareness as will treat- 
ment involving drugs, electro-convulsive shock therapy; behavior modification, and psychosurgery. These "innovative technological advances" are the latest development in the socially constructed response to an enduring social problem. The general historical form has been one of increasing effectiveness in isolating and stigmatizing the deviants rather than modifying those social conditions responsible for their suffering, although recent developments in family therapy and milieu treatment are resulting in the emergence of some attempts to counteract this trend.

\section{THE FALSE SCIENTISM OF PSYCHIATRY}

focusing attention on the contemporary condition of psychiatry will reveal additional problems in knowledge beyond those that have been raised in a sweeping discussion of its sociohistorical nature. The very fact that these factors are overlooked by the vast majority of contemporary psychiatrists would indict them of alienated consciousness as defined by Berger and Pullberg (1965:205):

seif, may be designated as false consciousness -
false in the sense that the actual process by which
itself and its world have been produced is for-
gotten. If this false consciousness achieves a
theoretical formulation, the latter functions as
a mystification (or, if one prefers, as an ideology
-). (emphasis in the original)

A mystification or ideology allows for a division of the social world into false categories such as "good" or "bad". The behaviors of people then can be viewed as a re- 
flection of the false category - in our case "mentally ill" (as opposed to "mentally healthy"). The various diagnostic subcategories of "mental illness" are extremely vague and unclear and as such can be used to stigmatize a wide range of behavior. For example, the label of schizophrenia is identified by Scheff (1975b:8) as a catch-all for a variety of "offenses" against the implicit norms of a culture. The similarities between diagnostic psychiatric categories like schizophrenia and omnibus statutes as they relate to juvenile delinquency are significant. As Gibbons (1976:13) observes, omnibus statutes mark off categories of behavior "that are so vaguely defined that nearly all youngsters could be made the subject of court attention."

The same shortcoming in the label of schizophrenia is unequivocally demonstrated in the research that is described by David Rosenhan (1975). He relates a research project in which eight researchers gained admission to twelve mental hospitals. In eleven of the twelve admissions the diagnosis of feigned hallucinations was schizophrenia. If we conceptualize this initial act as typification or stereotyping, as we discussed in Chapter II,* the dynamics of the labeling process will become clearer. The pseudopatients falsely re-

*In Chapter II we discussed Shur's (1973:120-126) notions of the labeling process as stereotyping, retrospective interpretation, and negotiation as he uses them in the context of juvenile delinquency. They are employed here to explain some of the dynamics of labeling insanity. 
ported only their initial hallucinations, their names (to avoid having the label of schizophrenia attached permanently), and their occupations (to avoid special or preferential treatment by virtue of being viewed as unfortunate colleagues). When questioned about their background and family relationships then, they responded with true accounts from their lives. Invariably this information reflecting the background and interpersonal relationships of the "healthy" pseudopatients was twisted in unbelievable ways to fit their new and "real" identity. The label intiated a process of retrospective interpretation by which all previous events were viewed as leading up to the current schizophenic episode. The patient thus is often subjected to a "prepatient" label which is linked to the "new" label which in this way is not really viewed as new. In fact, the original diagnostic session is characterized by Scheff (1975c:17) as focusing on what diagnostic category is to be employed rather than on whether the individual is in fact afflicted with a disorder. Once specific assignment to a category is effected the individual has acquired "a master status that excludes all other statuses from consideration" (Scheff, 1975e:77). This includes status as a genuine human being. The researchers in Rosenhan's account reveal the dehumanized nature of their new status. Now as subhuman beings there was little interaction with even the nonprofessional staff. In fact, the only way to operationalize the amount of interaction with 
patients was to measure the proportion of the attendants time spent outside the "cage" (i.e. the room, typically glassed-in, where records are kept and from which medication is dispensed). Attendants remained in the cage 88.7 percent of the time they were on duty. Moving up the hierarchical staff structure in the mental hospital less and less time was spent with the patients. Attempts to initiate interaction with the staff were either ignored altogether or, in some cases, resulted in beatings. The mental patient possesses little, if any, power to negotiate the nature of the relationship in which he or she is located.

While in the mental hospital there was no instance where either professional or nonprofessional staff recognized the "mental health" of a pseudopatient. In the first three hospitalizations in which records were kept, however, 35 of the 118 patients on the admissions wards detected the sanity of the investigators. In all cases, the pseudopatients diagnosed as schizophrenic were released as "schizophenics in remission." The investigators were kept in the hospitals for stays ranging from $7-52$ days ( $\bar{x}=19$ days).

How many people are unnecessarily admitted to mental hospitals? Admittedly this question is unanswerable but Rosenhan's research points to some measures offered by psychiatric personnel themselves. The staff at a research and teaching hospital doubted, upon hearing the above results, that the same thing could occur at their institution. The 
staff was told that in the following three months that pseudopatients would try to gain admission to their hosptial. During this period they were asked to rate all admitted patients as to whether or not they were genuinely "ill." of 193 patients admitted during the three month period 41 were judged by at least one staff member with high confidence as a pseudopatient. In fact, however, none of Rosenhan's investigators tried to gain admission to the hospital during the specifed period.

One doesn't need to expound upon the potential for oppression that is demonstrated by this research; it is only too frighteningly evident. Suffice it to mention that the depiction of mental hospitals offered by Ken Kersey in his novel, One Flew Over the Cuckoo's Nest (1962), is apparently rooted more in fact than it is in fiction.

The diagnostic activities of psychiatrists provide a false sense of scientific accuracy to what are really socially constructed categories that could be used to typify virtually anyone's behavior. The mere suggestion that one is "mentally ill" provides the basis for an unreflective quest for an adequate diagnosis as has been dramatically demonstrated by Maurice Temerlin (1975). He relates the findings of research in which a professional actor was employed to play the role of a normal, healthy, adult male. An interview was taped in which the actor posed as a mathematician who had read a book on psychotherapy and wanted to talk about it. 
The interview was recorded and played later to 25 psychiatrists, 25 practicing clinical psychologists, and 45 graduate students in clinical psychology. Just before hearing the interview a prestigious professional (a confederate of the experimenter) commented that the patient on the tape was "a very interesting man because he looks neurotic, but actually is quite psychotic." The subjects were asked to diagnose the man as either mentally healthy, neurotic (with specific diagnosis), or psychotic (with specific diagnosis). In response 60 percent of the psychiatrists, 28 percent of the clinical psychologists, and 11 percent of the graduate students diagnosed the actor as psychotic. No psychiatrist diagnosed the actor as mentally healthy while 3 of the clinical psychologists and 5 of the graduate students did. The remaining diagnoses were of some type of neurosis. In control groups that were employed there were no diagnoses of psychosis. That psychiatrists, especially, responded in this manner to suggestion raises serious questions regarding their susceptibility to suggestions made by family members, employers, and police officers.

Research done by James Greenley (1975) further supports the notion that psychiatrists merely legitimize the decisions made by other people regarding control of a person. Greenley investigated patients length of stay in a mental hospital as a function of the psychiatrist's diagnosis as to the severity of mental impairment and the combined effect of family and 
patient desires. The findings indicate that the psychiatrist's diagnosis bears little relationship to the length of the hospital stay when family and patient desires are controlled. The relationship between the latter factor and length of stay appears to have an impact "apart from the psychiatrist's estimate of the patient's psychiatric condition" (p.39). Although, as Greenley points out, the data aren't conclusive in terms of causal analysis they are clear in demonstrating that the psychiatrist-family-patient-hospital relationship is more a social process than medical one. The investigations made by Donald Caetano (1974) and Movahedi Siamak (1975) provide findings very similar to those of Rosenhan, Temerlin, and Greenley. Caetano's experimental findings provide evidence to support the contention that psychiatrists operate largely on the persumption of mental illness which severely biases their judgements at least in experimental settings. Siamak reports that over 90 percent of the biographies that were compiled by college students which were highlighted by their bleak experiences were judged by professionals to be characteristic of some type of psychiatric disturbance.

Other research points to the way in which psychiatry effects a discrimination on the basis of class in regards to admission to mental hospitals and the type of treatment that one receives. The classic study of mental health statistics in New Haven, Connecticut presented by August Hollingshead and Frederick Redlich (1958) revealed several interesting 
facts. Among them was the finding that the rate of treated "psychiatric illness" is three times higher for the lowest class as for the highest class (four class distinctions being employed, p.210). For patients in continuous treatment (over a six month period) the rate is 3.82 times higher for the lowest class. While 99 percent of the lowest class patients received treatment from state-provided hospitals and clinics only 9.6 percent of the highest class patients had to turn to these sources. The lowest class schizophrenics were receiving either custodial care or organic treatment (drug therapy, psychosurgery, shock therapy, etc.) in 90.9 percent of the cases while only 48.2 percent of the highest class schizophrenics received this type of treatment (insofar as you can refer to custodial care as treatment). While the picture is not particularly bright for any class in terms of "treatment" it still represents significant discrimination against those at the bottom of the social ladder. At this stage of investigation it would be premature to launch into a detailed analysis of the role of class distinctions in the etiology of mental disorders. The discussion of Marxism and mental illness in Roger Bastide (1972:18-21), however, raises the possibility of explicating the role of contradictions which are most extreme at the lower end of the social spectrum and the possible role of stressful conditions being most prevalent at this level is also mentioned. Unfortunately, Bastide merely mentions such possibilities without offering 
any extended analysis or development.

RESPONSES OF OPPRESSION TO CALLS FOR HELP

The discussion to this point should not be construed as an argument to the effect that there are not any people that are characterized by mental confusion, perceptual problems, inability to grapple with aspects of reality that are necessary for existence, and so forth. The contention is that the medical model and the traditional theories of psychiatry do not give us even a modicum of understanding about these problems of living; what they are, where they originate in human social relations, or how they might be solved meaningfully.

We can begin to formulate answers to these questions only by viewing the sometimes bizarre and confused communications of seemingly insane people as complaints about oppressiveness in their social environments or simply as frantic calls for help. To localize the problem within the individual is to respond with further oppressiveness to those calls for help.

Taking the fragmented and "crazy": communications of individuals experiencing cognitive distress seriously is a solid theme running through most of the "antipsychiatry" literature. Tackling these messages represents a difficult task at best. Laing at one point suggested a useful strategy which, unfortunately, he has failed to develop. 
As we begin from microsituations and work up to macrosituations we find that the apparent irrationality of behavior on a small scale takes on a certain intelligibility when one sees it in context. one moves, for example from the apparent irrationality of the single "psychotic" individual to the intelligibility of that irrationality within the context of the family. The irrationality of the family in its turn must be placed within the context of its encompassing networks. These further networks must be seen within the context of yet larger organizations and institutions. These larger contexts do not exist out there on some periphery of social space: they pervade the interstices of all that is comprised by them. (Laing, 1969:15)

Still the analysis framed by laing moves little beyond the analysis of "psychotic" irrationality made more rational by viewing it in the context of the family. What is needed is a fuller understanding of "psychotic" behavior as a problem in the sociology of consciousness and knowledge. Berger and Pullberg have touched on this probiem as far as contending that consciousness and mental health are culturally relative. To challenge alienated consciousness is to place oneself in jeopardy of being defined as mentally "unhealthy" and also removes one from full participation in the social constructions of reality. Alienated or false consciousness, strangely enough, may be defined as mental health or stability which ipso facto places the seeing through of alienation and reification, or the development of true consciousness, at the very edge of "sanity."

It [isn't] necessary or even likely that an alienated consciousness is subjectively experienced as psychological "health" is a function of the social situation. If the latter is defined in alienated terms, then only those who share this definition will be psychologically "healthy". For instance, 
in a society that understands it institutions as an interaction between divine and demonic forces, an understanding of these institutions in other terms is likely to be allied with a psychologically "unhealthy" condition or will lead there if held on to stubbornly in the face of the socially acceptable explanation of the world. (Berger and Pullberg, 1965:200)

Therefore the possibility emerges for the person who finally sees through the "insanity" and oppressiveness of the world of today and who proposes a "sane" alternative that he or she may at that very point be close to insanity by virtue of not being able to share and thus construct the necessary social dimensions of reality (i.e. objectivation and objectification) for want of common symbols and sentiments. This insight helps us understand and extend Kupers' (1976: 119) discussion of the possibilities of personal stress and confusion that may be experienced by one who refuses to be numb to the reification that occurs in everyday life.

Some individuals more than others, for some reason, refuse to be . . . numbed. But when they proclaim their beliefs, at whatever level of development, they are denied validation in the areas where their beliefs contradict the conventional consciousness. Repeated enough, in the right combination, this devalidation can create areas where these people are unable to evaluate the truth or merit of their own perceptions and beliefs. They cannot test social reality because they have no way at that moment to challenge the united presentation of the conventional view by significant others in their lives. If they refuse to surrender or alter their course, seemingly sporadic events may add up to a consistent pattern whereby they may become unable to differ with the increasingly consolidated attribution by others that they are first different, then strange, and finally mad.

Similar, but less insightful observations are made by John 
Berger (1974:135), Halleck (1971:21-26), Cooper (1973a:155), and Laing (1973a:75-94).

Two other general pathways lead from conventional reality to some other perception or behavioral mode. The first is the mystification of oppression and the second is defective socialization.

When the source of oppression is mystified and "hidden" from the direct perception of an individual the response is likely to be one of frustration that is expressed inappropriately. A very oversimplified everyday experience is illustrative of this general response. Often while carrying on a conversation one or both parties begins acting rather nervously; fidgeting, squirming - the tenor and volume of the conversation go up as tolerance and rational thinking go down. Finally, one member suddenly jumps up and turns off a loud television, radio, or stereo; for a length of time the source of frustration and anxiety was not perceived. As soon as it was perceived solution of the problem was straightforward. Life, unfortunatley, is not always so simple. The alienation and reification that pervades modern industrial life obscures and mystifies the various sources of oppression and frustration. Added to this already clouded consciousness is the mystification one thrusts upon oneself by virtue of the fear that is experienced when one does uncover the source of oppression; one sure way to elicit increased oppression is to identify its 
source. If this problem is not initially perceived by the oppressed individual or group its stark reality is thrust upon them after protests, complaints, or observations have been vocalized. Thus, as Szasz (1974:124) points out, an individual may mask his or her complaints in very bizarre ways; what he refers to as protolanguage. This form of communication serves its user in a manner similar to the way in which Latin terms used to refer to sexual organs do; they allow one to address delicate subjects while disowning distrubing implications. Hysteria, according to Szasz, is the employment of bodily signs as a general request for help. These signs mean something very different for the therapist with a medical orientation. The person may indeed acquire someone to listen to their complaints which would tend to reinforce the use of bodily signs and would also keep the therapist from really "hearing" the complaints. The person communicating in this manner may be very successful in getting the psychiatrist to accept the role they are playing but inevitably the actor gets typecast - a professional actor's most dreaded disease, because thereafter they will never be accepted in another role (p.244-245). This is an inherent feature of traditional psychiatry according to Szasz; the result of a misplaced focus on "mental illness" rather than on communications. Therefore the patient speaking and listening in terms of complaints engages in a lopsided relationship with a psychiatrist who is listening and 
speaking in terms of mental illness; the patient will inevitably shift over to the perception of reality inherent in the latter mode. The focus is now on internal factors rather than the distressing aspects of one's environment. To Szasz (1974:246) this is:

- . the situation in which most persons called mentally ill now find themselves. By and large, such persons impersonate the roles of helplessness, hopelessness, weakness, and often of bodily illness - when, in fact, their actual roles pertain to frustrations, unhapinesses, and perplexities due to interpersonal, social, and ethical conflicts.*

Discussion of the idiom of demonic possession in Gananath Obeysekere (1975) provides cross-cultural support for Szasz's contentions. Obeysekere relates the case of a Sinhalese woman living in an oppressive family and marital environment butressed by an extremely misogynic culture. The woman voices her complaints via the well defined cultural idiom of demonic possession. Much like the case of the Western hysteric, our Sinhalese woman is typecast in the role of the demon-possessed person. Thus, she must go through all of the prescribed religious ceremonies. In adhering to the idiom of demonic possession she gains several valuable things although she still lives in virtually the same conditions as before albeit.with a new role: she gains the ear and sympathy of husband, priest, family, and com-

*Szasz is quick to point out that this impersonation is not always a consciously planned strategy, though often it is. 
munity; and, in the midst of the religious ceremonies "spirits" speak through her often voicing requests which when granted provide some niceties for her.

There are two general sources of defective socialization; biological disorders and family structures that preclude "normal" sociopsychological development of children. The first source is fairly self-evident so we won't take it up here (this does not represent a denial of the relevance of factors related to oppression, however). The second source has received much attention as a result of Gregory Bateson's (1972) observations regarding the "double-bind" structures in the families of schizophrenics. An interesting study performed by Morton Schatzman (1975) reveals the potential relationship between cruel or oppressive childrearing practices and sociopsychic distresses. The study is especially interesting because the subject, Daniel Schreber, was analyzed by Freud. Although Freud and Schreber never met, Freud analyzed his disorder by using his published memoirs as data. As Schatzman points out, however, Freud overlooked the importance of another source of data that still exists. These data are the eighteen books and booklets written by Schreber's father who was a physician, orthopedist, and pedagogue. Many of the elder schreber's writings are about his methods of child-rearing; methods he applied to his own children. Freud knew of schreber's father and, if interested, could have learned (if in fact, he didn't 
know) that Schreber's older brother shot and killed himself at age thirty-eight. Schreber, more "fortunate," became a mental patient at forty-two and spent thirteen of his last twenty-seven years in mental asylums, where he died. sadly, the irony goes further:

Irony is everywhere. An eminent pedagogue has a psychotic son; it does not hurt his reputation. Freud, an avid reader, neglects books on child rearing - as do his followers - by a man whose son's childhood experiences he tries to derive. German parents rear their children by the ideas of a man whom many people now would see as sadistic or mentally ill. (Schatzman, 1975:93)

In the case of Schreber the dialectical relationship between a cultural level of knowledge or consciousness and its reflections and its reciprocal supportive role in microlevel structures like the family are open to view. These issues will be taken up in the next chapter in our discussion of the politics of the family.

Though Berger and Luckmann say very little regarding the incidence of insanity their general observation that reality maintenance in society is relatively successful and that therefore insanity will be relatively uncommon provides a necessary backdrop to our discussion. These challenges to socially constructed reality will not be serious as long as they can be diffused and localized within individual people. Should numbers of people begin sharing an alternative conception of reality then the danger of a massive societal shift in realities is present. Such "mass madness" (i.e. revolution) is feared because the outcome is unknown. 
Conditions of life may be more or less desirable at present; in any case they are certainly more concrete than what is known about the future. Massive transformations are indeed rare, and therefore this minimal reality shifting of insanity can be handled ordinarily by an aspect of the conceptual machinery of symbolic universe-maintenance referred to by Berger and Luckmann as therapy.

Therapy entails the application of conceptual machinery to ensure that actual or potential deviants stay within the institutionalized definitions of reality, or, in other words, to prevent the "inhabitants" of a given universe from "emigrating." It does this by applying the legitimating apparatus to individual "cases". . Therapy in one form or another is a global phenomenon. Its specific institutional arrangements, from exorcism to psychoanalysis, from pastoral care to personnel counseling programs, belong, of course, under the category of social control . . . Since therapy must concern itself with deviations from the "offical" definitions of reality, it must develop a conceptual machinery to account for such deviations and to maintain the realities thus challenged. This requires a body of knowledge that includes a theory of deviance, a diagnostic apparatus, and a conceptual system for the "cure of souls." (Berger and Luckmann, 1967:112-113)

Powerful institutional forces are responsible for keeping sociopsychic problems within the framework of a medically oriented psychiatry. Medicine and psychiatry are in themselves very powerful social institutions which ipso facto will be very difficult to change; and yet our analysis demands that very thing. Western psychiatry is a classic example of the class struggle. Its positions are typically filled with those of elevated status and privilege endowed with the power and predilection to treat men and women as 
commodities; as purely objects. Its practice is enshrounded with alienation, reification, mystification and ideology.

An additional significant source of support for the maintenance of the ideology of mental illness resides in the nature of the politics of everyday life. These political structures are able to maintain their distributions of power even when challenged by referring the challenger to the psychiatrist as an either severely neurotic or psychotic "case." As we have already evidenced, this presentation of the "case" as one of mental illness tends to predispose the context to one in which the goal is an appropriate psychiatric diagnosis. By providing such a category and the dynamics involved in doing so the challenger is "cooled out" and the political structure is maintained.

Responses to calls of sociopsychic distress that are not oppressive would attempt to decode and interpret the inappropriate or unconventional communications coming from the "insane" person. An appreciation of, and a sensitivity to, the problems of consciousness on the part of a helping agent in these situations is crucial. When these insights are shared with the person in distress they could be instrumental in minimizing the terror and fear one experiences by virtue of "breaking out" of previous perceptions of reality. This should help to facilitate interpretation of "psychotic" communications that will enable the "therapist" to devise alterations in the individuals family, school, or work en- 
vironment to promote a more livable situation for the distressed person. In her discussion of psychiatric treatment in China, Ruth Sidel (1975) suggests that superior success in treatment there is based upon procedures and techniques that promote interaction with the patient, not isolation as is the case in Western mental hospitals. She shows how the patient is progressively worked back into social relationships when particularly oppressive or distressing dimensions of those relationships have been altered by the therapists involved with the patient. Though Chinese psychiatric treatment has some serious drawbacks it does suggest some very fruitful alternatives to traditional western psychiatric practice. 


\section{THE POLITICS OF EVERYDAY LIFE}

In Chapter II we discussed the possibility of grappling with the reality of everyday life in terms of analysis of its political features in relation to the family, school, and workplace. It should be stressed that this is but one dimension of these structures. In this type of analysis our attention will focus upon the various similarities with "macropolitical" phenomena. This will help to sensitize us to the role of discrediting labels in the maintenance of these "micropolitical" structures. Perhaps the most significant similarity is the fact that power or authority is distributed inequitably within the political structures of everyday life. Thus, in terms of decision-making, for example, not all parties involved in living under the existing conditions of a relationship have equal power in affecting the decision-making from which the conditions derive. How much say that children, students, or employees have in the decision-making process is up to the discretion of parents, teachers (and administrators, school board, etc.), and employers. This is not to say that all parents, teachers, and employers are, therefore, oppressive in terms of the power that they possess; the point is, that the poten- 
tial for oppressions does exist. There is, however, an inherent predisposition toward oppression in that these structures tend to focus on the needs of those possessing power rather than the needs of those who don't. This feature is inherent within these structures inasmuch as the needs of those without power are not vocalized within the decisionmaking process by virtue of being excluded from it except as they are perceived by those with power in these spheres. In American "macropolitics," for example, those with financial power can affect decisions in their favor by financing a program of lobbying in which their needs are vocalized within the decision-making process; those with less resources are incapacitated in this regard.* Those without financial clout must often voice their needs through demonstrations, rallies, or other forms of dissidence. similarly in the family, for instance, a youngster may resort to protest to vocalize his or her needs. In "macropolitics," as we have already mentioned, protestors are often labeled as "traitors" or "anarchists" or some such label which serves to discredit both them and their protests. In "micropolitics" protesters are often labeled with psychiatric tags which serve to discredit them and their contentions in the service of maintaining the existing structures involved.

Obviously financial power in American politics is employed in more ways than lobbying, but this aspect is raised simply to illustrate the similarities within the politics of everyday life and "macropolitics." 
The structures of family, school, and workplace overlap extensively and to deal with them separately necessitates an understanding of their dialectical interrelationships. Each structure helps to reinforce or reify the others by emphasizing different aspects of the same cultural theme. In American society the theme which is of importance to us in this analysis is that of dominance/submission. There are other themes that both overiap with this one and support it in addition to being supported themselves by this basic theme. The family is of primary concern in this discussion by virtue of being the primary socializer for society and therefore considerably more space will be devoted to it.

\section{THE POLITICS OF THE FAMILY}

The family is the fundamental agency by which a person gains entrance into social reality. Ipso facto the family mystifies consciousness in that it is thrust onto the infant as a given. Berger and Luckmann explain this feature of primary socialization in a manner that allows us to perceive the original source of mystification that confronts one in the process of socialization.

Society presents the candidate for socialization with a predefined set of significant others, whom he must accept as such with no possibility of opting for another arrangement . . This unfair disadvantage inherent in the situation of being a child has the obvious consequence that, although the child is not simply passive in the process of his socialization, it is the adults who set the rules of the game. The childtran play the game with enthusiasm or with suller resistance. But, 
alas, there is no other game around . . The child does not internalize the world of his significant others as one of many possible worlds. He internalizes it as the world, the only existent and only conceivable world . . Primary socialization thus accomplishes what (in hindsight, of course) may be seen as the most important confidence trick that society plays on the individual - to make appear as necessity what is in fact a bundle of contingencies, and thus to make meaningful the accident of his birth. (Berger and Luckmann, 1967:134-135) (emphasis in the original)

The insight offered here points to an inherent problem of oppression in socialization that is subject to either intensification or some degree of liberation. While both are objectively possible the former is much more likely than the latter for a number of reasons. The prospects for liberation from a unidimensional perception of reality are predicated upon an understanding on the part of the parents concerning the nature of social reality. It is not likely that this would inevitably follow simply as the result of the educational experiences of the parents, as the sociology of knowledge is not integrated into the structure of traditional education. When liberation from constricted perceptions of reality does occur it usually operates from the experiential base of a parent who has rejected the Weltanschauung of his or her own family and adopted another one, or, in the case of the truly marginal person, a number of others. This experience "teaches" one that the world of the family is something less than inevitable and this knowledge can be transmitted to children. Obviously this outcome is not very likely for many families. On the other side, there 
are definite political advantages in getting children to accept the existing parental world, not the least of which is a ready-made legitimating mechanism for their authority and power. In other words, unquestioning acceptance of this world will ipso facto promote unquestioning acceptance of the parents behavior. This will both save time and make matters much more manageable. What would necessitate considerable thought and effort (e.g. an answer to the inquisitive child's "Why?") is answered with a simple "because." Not only does this save time in the immediate situation but it also discourages the child from asking the question again in the future. It also informs the child that everything is all right as it is; the simple response "because" carries with it the message that the status quo is both legitimate and obvious. The more oppressive response, "because I said so!", speels out the distribution of power in the family quite explicitly for the child. It may be accompanied by more stringent sanctions which help to hasten the process by which the child generalizes these experiences to the inhibition of questioning anything. This makes the family more manageable and will also help the youngster "fit in" the classroom and the work-place. In societies characterized by themes of dominance/submission children "are trained to obey commands by superiors in pursuit of fixed goals rather than to negotiate with equals in response to changing conditions." The organizing principles of this type of 
society are "hierarchy, predictability, and control" which are "symbolized by the assembly line, the clock and calendar, and the budget - lifeless apparatus to which human beings are yoked like beasts of burden. The ideal person for such servitude is one who is reliably obedient, predictable, and orderly" (Scheff, 1975e:80). Families successful in this type of socialization rejoice in having a child that is "good" in school and who will be "reliable" on the job. In capitalist societies, where bureaucracy abounds and functions best with this type of worker, these aspects of socialization are especially emphasized. This is not meant to be a unilinear argument of causality postulating that capitalism causes sociopsychic distress. Some of these same organizational forms and interrelationships exist in a variety of cultures. It merely points out the fact that these types of socialization objectives exacerbate the already inherent mystification of consciousness that exists in the nature of the family. As Kupers (1976:118) contends, this type of society promotes socialization practices which disavow the existence of oppression even in the very midst of it. This we have noted before in his observation that the child is "encouraged to ignore or be numbed" to certain aspects of the environment. The child is encouraged, for example, to be "numb to parental deception" and to "rationalize that even blatantly arbitrary punishment is 'for his own good' " (p.119). In the case of Schreber, to which we referred 
earlier, Schatzman demonstrates in an analysis of Dr. Schreber's (Schreber's father) writings on child-rearing that the emphasis was on the total unquestioning obedience of the child for the child's own good. A passage from his work quoted by Schatzman (p.106) illustrates this tactic of using various types of punishment in order to be:

. . master of the child forever. From now on a glance, a word, a single threatening gesture, is sufficient to rule the child. One should keep in mind that one shows the child the greatest kindness in this in that one saves him from many hours of tension which hinder him from thriving and also frees him from all those inner spirits of torment which very easily grow up vigorously into more serious and insurmountable enemies of life. (D.G.M. Schreber, $1858: 60-61$ )

The "delusional" response of the younger Schreber was that "God himself was on my side in his fight against me" (Daniel P. Schreber, 1955:79). Dr. Schreber advocated a parental stance that was directed to instilling the belief in the child that not only was it wrong for him to keep things from the parent but that it was not even possible. As Berger and Luckmann imply, if the child maintains participation in this parental world he or she will, in fact, be incapable of keeping anything from the parent. What are the implications of these situations in which a child is not permitted to develop autonomy of thinking? From a Meadian perspective one can speculate as to a breakdown in the development of communication between the "I" and the "me" in that making indications to oneself about external events would be severely constricted. In fact, one could question 
the real possibility of the full development of a "self" in such contexts. Laing provides some relevant observations on this point in his discussion of the case of a chronic schizophrenic girl (Julie) and her family relationships. The mother in this case related to Julie as a mere extension of herself in a manner that disabled her to develop any autonomy. As Laing (1973a:81) puts it: "genuine self-action seems never to have become established to any extent, but instead all action is in total compliance and conformity with outside directives." At an early age Julie therefore did all of the "normal" things that children do with a subtle distinction "In Julie's case, her actions appear to have been trained by her mother, but 'she' was not 'in' them." Later we will pick up at the point at which her "normalcy" became "madness," but for now let's examine Laing's observations regarding Julie's psychotic episodes. He recounts that, although it was possible "to carry on a verbal exchange of a kind, but without her seeming to have any overall unity but rather a constellation of quasi-autonomous partial systems, it was difficult to speak to 'her' "(p.95). Though one sees process (the "I," according to Mead) there is little evidence of structure (the "me"). In such a case reflective consciousness would appear to be an impossibility. This in mind, consider Laing's following observation (p.97):

In so far as reflective awareness was absent, "memory," for which reflective awareness would seem to be prerequisite, was patchy. All her life seemed to be contemporaneous. The absence of a 
total experience of her being as a whole meant that she lacked the unified experience on which to base a clear idea of the "boundary" of her being.

It would undoubtedly be legitimate to contend that Meadian social psychology would allow that a nonhuman animal could have an "I" (i.e. a minimal biopsychological functioning) but it would firmly deny the possibility for this organism to possess a "me." Conversely then, if a person like Julie were denied whatever minimal autonomy is necessary to develop a "me" then there would either be fragmented partial "me's" as "chunks" of memory but no coherent "me" capable of thinking or intrapersonal interaction in the Meadian sense; the person would simply exist as an "I." This point requires much further investigation and clarification, but such an endeavor falis outside of the immediate scope of this paper. The point to be made is that oppressive factors in the family may seriously disable the person's ability to identify and object to that oppression; such persons are locked into a type of "double-jeopardy" situation. That is to say that they may be subjected to oppression which results in a break-down in normal development of the "self" in the first place which leads to unconventional modes of reacting to that oppression in the second place.

What kind of political problems are raised for the family when protests, however inappropriate or bizarre, are "vocalized" or communicated? If the protests are taken seriously and viewed within the family and the family within 
increasing macropolitical structures, then alteration of structures and redistributions of power have to be viewed as alternatives. History provides one unequivocal observation in this regard: those in positions of power are the least willing to deal with change as a viable alternative. In most cases this is not even a possible conception for the persons with power; reality for them is static and nothing else is real or legitimate; or alternatives are perceived as threatening to that power. Within "macropolitical" and "micropolitical" contexts it is easiest to handle the discomfort of dissidence or protest by labeling it as "treasonous" in the former case and as "mental illness" in the latter. The legitimating structures identify the dissidents as obviously "criminal" or obviously "mad," respectively. In both cases the argument seems logical because there are very similar "deviants" whose deviations are not the direct expression of protest. One points to criminals that violate the value system of the society by "acquiring goods" that they have not purchased and to which they have no "legal" claim. The political dissident also violates the value system by criticizing it in its institutional forms; a misguided logic equates the two violations. One also points to persons with observable organic defects whose violation of norms of behavior include no direct protests. An equally misguided logic contends that similar norm violations are the symptomatology of some other less observable "organic" 
defect. In both cases labels are employed to discredit the protester. According to Scheff (1975d) the ambiguity of what "mental illness" is and the collusion of family members against the prepatient results in many questionable commitments. In Julie's case Laing ciearly unmasks the dynamics of discrediting labeling in an effort to maintain the power distribution in her family.

- * the original pattern of her [Julie's] actions was entirely in conformity with what ner parents held to be good and praiseworthy. Then, she was for a time "bad," that is those very things her parents most did not want to see her do or hear her say or to believe existed in her, she "came out with." We cannot at present say why this was so. But that she was capable of saying and doing such things was almost incredible to her parents. All that emerged was totally unsuspected. They first tried to discount it, but as the offense grew they strove violently to repudiate it. It was a great relief, therefore, when, instead of saying that her mother wouldn't let her live, she sajd that her mother had murdered a child. Then all could be forgiven. "Poor Julie was ill. She was not responsible. How could I ever have believed for one moment that she meant what she said to me? I've always tried my best to be a good mother to her." (Laing, 1973a:74)

Yes, poor Julie; her "psychotic" communications have no basis in reality. That is obvious because the poor girl says some extremely bizarre things: "a child has been murdered"; "I'm a tolled bell" (or "told belle"); "I'm tailor-made" or "I'm a tailored maid"; and, "this child is dead and not dead." David Cooper (1973b:163) relates a similar case of an eightyear-old boy diagnosed as a schizophrenic in "autistic withdrawal."

This beautiful boy of eight was brought into my 
room by his mother and father, and he wore a badge saying, "It's wrong to eat people." He grimaced and gesticulated and could not (or perhaps more relevantly, did not want to) sit in one place and take part in the discussion. His mother . . Was consuming the child in terms of an orientation of her whole mind and body to his "welfare" - protecting him from rough friends at school and an overly punitive headmaster who smelled out a "wrong one." But she was erecting this abdominal wall around her son because she was being starved, in terms beyond the sexual, by her husband, who taught at aniversity west of London. He was starving her because he was being starved of any sort of real intercourse with others by academic bureaucracy, which mediated to him the first-world famine situation (which seems to be hardly recognized by university administrators, but which is protested with increasing frequency by radical students - with increasing effect).

Although some of Cooper's observations are a bit dated and some of his semantics imply a psychoanalytic framework that we would reject here, he does make a couple of things clear. First, that the youngster's communications related in a real sense to his family situation and were indicators of its oppressive components. Secondly, Cooper seems to grasp the critical role that general cultural themes that are reflected in work, school, and family play. It would be hard to overemphasize the importance of this dialectical relationship. It is also demonstrated in the schreber case. One of Dr. Schreber's child-rearing books sold nearly forty editions and was translated into seven languages. How could such a parental failure advocating "torture chamber" measures (e.g. cold water baths at six months of age to toughen up the baby, and a series of restraining devices to promote good posture) be a popular source of parental education? 
The observations made by Schatzman suggest the existence of cultural legitimations that supported Dr. Schreber's approach; this could have been the popularity of the moral stance of harsh discipline to establish strong will power to withstand temptation. That his authoritarian approach was so widely employed suggests that the theme supporting his approach was itself modified through its intensification. Schatzman (1975:116) suggests that we "remember that Hitler and his peers were raised when Dr. Schreber's books, preaching household totalitarianism, were popular."

The form of social relations in capitalism tends to heighten the problems in autonomy that we have discussed in that children within the family tend to be viewed as objects or commodities. In the following passage Juliet Mitchell (1976:204-205) points out an important factor in oppression and the mystification of consciousness within the family.

At present, reproduction in our society is often a kind of sad mimicry of production. Work in a capitalistic society is an alienation of labor... maternity is often a caricature of this. The biological product - the child - is treated as if it were a solid product. Parenthood becomes a kind of substitute for work, an activity in which the child is seen as an object created by the mother, in the same way as a commodity is created by the worker. . . The child as an autonomous person, inevitably threatens the activity which claims to create it continually merely as a possession of the parent. possessions are felt as extensions of the self. The child as a possession is supremely this. Anything the child does is therefore a threat to the mother herself. . . There are few more precarious ventures on which to base a life. (emphasis in the original)

One is amazed at the degree to which mothers "compete" via 
their "products." The comparisons and "one-upmanship" that often occurs between mothers reminds one of owners showing off the qualities of their possessions such as automobiles, paintings, houses, and so on. That women will often "train" their youngsters to do the "tricks" that grant her prestige or honor places undo pressures for the obedience of the child.

Having dealt at some length with the politics of the family we have overlapped in some ways the relevant aspects of the politics of school and workplace. We will now, very briefly, focus our attention on these areas of everyday life.

\section{THE POLITICS OF THE SCHOOL}

What the child is exposed to in the school is a series of dulling and mystifying experiences in which he or she is trained to accept authority regardless of its specific characteristics. That schools, in conjunction with other structures (especially the family and workplace), have been successful in this effort is evidenced in a variety of ways. One strong indicator comes from the littie research that has been done on obedience such as the Milgram study. This is the least painful way for society to measure the success of its oppressive ideological apparatus. More painfully we are forced to learn (more accurrately, we have failed to learn) from the inhumane behavior witnessed at Auschwitz, My Lai, and kent state, for example. The schools continually func- 
tion to legitimate what is arbitrary authority in the family. In "Death at an Early Age" Jonathan Kozol (1976:386), a school teacher, explains the damaging nature of schooling in Boston.

. the whole concept of respect for unearned
and undeserved authority is bitter and brittle and
back-breaking to children, whether rich or poor, or
black or white, within these kinds of schools :
No child in his heart, unless drugged by passivity,
will pay obeisance to authority unles authority
has earned it. . There is too much respect for
authority in the Boston schools, and too little re-
spect for the truth. If there were more of the
latter, there would be less need of the former, and
the atmosphere of the Boston schools would not have
to be.
torship in the atmosphere of a crumbling dicta-

In recent years schools have been under attack as failing to educate students as they should. In their analysis of this "failure," Paul Lauter and Florence Howe (1976: 390-408) suggest that schools have really been "very, indeed horryfyingly, successful" (p.392). Lauter and Howe call attention to the objectives that parents and employers envision for schools in America. They refer to a Harris poll showing that 62 percent of the parents questioned thought that "maintaining descipline is more important than student self-inquiry" (p.394). They contend that schools have "served the desires of business for a disciplined and acquiescent work force" (p.394). The schools have, by and large, according to their account, been instrumental in continued oppression of those at the lower end of the social spectrum through maintenance of the status quo. 
The confusion and obfuscation of educational goals merely serves to mystify the development of consciousness in this country. Schools pick up where the family needn't tread to extend what Kupers, (1976) as we have discussed earlier, refers to as numbness. He suggests that the school is responsible for passing on deceptions regarding the history of capitalism. Obvious to Laing $(1973 \mathrm{~b}: 110)$ is the role of schools in "the mystification of experience."

In order to rationalize our industrial-military complex, we have to destroy our capacity to see clearly any more what is in front of, and to imagine what is beyond, our noses. Long before a thermonuclear war can come about, we have had to lay waste our sanity. We begin with the children. It is imperative to catch them in time. Without the most thorough and rapid brainwashing their dirty minds would see through our dirty tricks. Children are not yet fools, but we shall turn them into imbeciles like ourselves, with high IQ's if possible.

As the contradictions of our world are internalized by children then they too can share and propagate the mystification of reality. In this way, according to Laing (1973b: 124), "the texture . . of these socially shared hallucinations [becomes] what we call reality, and our collusive madness . . what we call sanity."

The school encounters dissidents and disposes then in the manner of discrediting through labeling. Students are labeled either as "behavior problems" or mentally disturbed if they don't fit in "smoothly" to the bureaucratic organ- 
First, a few comments regarding alienation in the context of insanity. When the workplace is characterized by extreme alienation at least two things occur. One, the male worker inevitably carries the numbing experience of work home to his family where, being the possessor of virtually unlimited power, he may respond oppressively toward his wife and children out of feelings of frustration, powerlessness, and irritation. He often learns various techniques in oppression from his employer and incorporates these features of oppression into his own family structure. Another very real consequence of experiencing alienation in the workplace is the desire to be "free" and "autonomous" while not on the job. The typical strategy to effect this is to emphasize that aspect of life that does not, in his perception, belong to the boss. In the process of privatization, however, the worker finds himself in the role of consumer as he turns toward "fulfillment" in campers, boats, summer homes, expensive vacations, and so on. To purchase these commodities he finds himself ever more tightly bound to the workplace. Often he takes on another job to "make the payments." The result is that the worker is even more numbed to his alienation than before. He is also modeling, and very often vocalizing, a work ethic for his children. He begins to perceive his role toward them in terms of their own preparation for the workplace.

The special case of paranoia in the workplace has been 
ization.* The psychiatrist has played a vital role in this process according to Simon Madison (1973:127), showing his usefulness in "his ability to label what is seen to be threatening behavior as manifestations of mental illness."

Here as in no other place there is a deluge of recordkeeping which effects almost continuous monitoring of the student's behavior beginning with preschool. A common notation on these records follows the form "needs more selfcontrol." Taken very literally this concern of teachers, parents, and administrators reflects a general objective of schools within society: To make the youngster "obedient, predictable, and orderly" in order that he or she will be ideally suited for "the assembly line, the clock and calendar, and the budget" (Scheff, 1975e:80).

THE POLITICS OF THE WORKPLACE

Much of what we have said up to this point overlaps with a discussion of the politics of the workplace and much work has already been done in this area especially in terms of alienation. Therefore we will deal very briefly with a few of the most relevant political factors of the workplace.

*

It is an interesting problem of knowledge that resulted in the late $1960^{\prime} \mathrm{s}$ on college campuses and many high schools when there was a "collective" movement or deviance that effected some changes, however minimal. It becomes difficult to label these dissidents as a "collective behavior problem" and therefore a shift to label these students as "communists", "radicals", or some such label to discredit their complaints about the bureaucratic sterility of education 
First, a few comments regarding alienation in the context of insanity. When the workplace is characterized by extreme alienation at least two things occur. One, the male worker inevitably carries the numbing experience of work home to his family where, being the possessor of virtually unlimited power, he may respond oppressively toward his wife and children out of feelings of frustration, powerlessness, and irritation. He often learns various techniques in oppression from his employer and incorporates these features of oppression into his own family structure. Another very real consequence of experiencing alienation in the workplace is the desire to be "free" and "autonomous" while not on the job. The typical strategy to effect this is to emphasize that aspect of 1 ife that does not, in his perception, belong to the boss. In the process of privatization, however, the worker finds himself in the role of consumer as he turns toward "fulfillment" in campers, boats, summer homes, expensive vacations, and so on. To purchase these commodities he finds himself ever more tightly bound to the workplace. Often he takes on another job to "make the payments." The result is that the worker is even more numbed to his alienation than before. He is also modeling, and very often vocalizing, a work ethic for his children. He begins to perceive his role toward them in terms of their own preparation for the workplace.

The special case of paranoia in the workplace has been 
discussed by Edwin Lemert (1972). Paranoia as dealt with here by Lemert relates to bureaucratically organized work more than to factory or assembly line work per se. In these complex organizations a multitude of informal procedures and sanctions are incorporated into its everyday functioning in addition to those that are formalized. To point these out very often consitutes a serious faux pas in the perception of one's superiors in an organization. As Lemert (p.251) puts it:

The individual is an ambiguous figure whose behavior is uncertain, whose loyalty can't be counted on. In short, he is a person who can't be trusted because he threatens to expose informal power structures. This, we believe, is the essential reason for the frequently encountered idea that the paranoid person is "dangerous."

The "paranoid" person may perceive, for example, that an informal meeting between powerful figures has preceded the ongoing formal meeting; the former meeting having been the one in which the decisions were really made. If the "paranoid" (more accurately something like the "perceptive one") is so indiscreet as to point out this informal procedure, he or she will thus initiate an uncomfortable and embarrassing episode. Uncomfortable in that confrontation, a rare thing in "manipulated meetings," is open and direct; embarrassing because the real distribution of power is laid bare. What Lemert observes is that the informal and formal mechanisms respond quickly to exclude the "paranoid" from participating in matters in which he or she could further 
disrupt the smooth "normal" operations of the organization. One way is to place the "paranoid" in a "harmless" job. Another is to systematically restrict his or her access to important information and processes. A third strategy is to affix the label "paranoid" to the individual. It is relatively easy to legitimate the label in that many formal or procedural rules can be called into play to discredit the "paranoid's" insight. A superior, for instance, could respond by saying: "Now, John calm down. Yor're just upset. You know as well as I do that this committee operates according to specified procedure. Don't be so paranoid!" The systematic exclusion of the "paranoid" will very often effect a self-fulfilling prophecy of these earlier allusions to his paranoia. If he maintains his indiscreet posture he may soon find himself fired on psychological grounds as he responds to the exclusionary tactics of his associates. He may also find himself in a mental hospital grappling with the same dynamics in a different setting.

In all forms of the workplace any effort to organize labor is met firmly with a strategy of discrediting labels. The history of the labor movement is one of allusions to criminality, treason, communism, and other deviant categories on the part of labor organizers. The relative lack of enthusiasm to organize on the part of workers attest to their own mystified or reified consciousness or numbness emanating from the collusion of family, school, workplace and supportive 
legitimating ideologies such as psychiatry and criminal justice in the use of discrediting labels to maintain socially constructed realities. 
CHAPTER V

\section{A RADICAL MODEL FOR INTERPRETING}

\section{SOCIOPSYCHOLOGICAL PROBLEMS IN LIVING}

A serious danger at this point in any argument would be to unquestioningly accept the proposed perspective on the basis of its plausibility. This very problem has been identified as a central feature of the critique of traditional psychiatric approaches that this paper has offered. Important questions must be asked and acceptable answers given lest we "launch off" on another myth-ridden journey into the human mind. For example, what does this perspective on mental distress predict? What findings would lend support to this approach? A strategy for the presentation of such issues that will be employed in this chapter is the development of a set of propositions and corollaries that should be tested to provide indications as to the acceptability of a radical sociology of knowledge framework in the analysis of insanity. A major advantage of this tactic is increased clarity of the approach by virtue of its explication in propositional form. In the development of the propositions that follow attention is focused primarily upon theoretical content and their implications. Therefore all of the methodological issues raised by a particular proposition will not be addressed here. 
Suffice it to say that adherence to a strictly positivistic approach is not the answer to the majority of research questions that are generated by the following propositions. Those questions are necessarily characterized to a large degree by phenomenological inquiry and sociohistorical analysis for which strict positivism is poorly equipped (which would seem to demonstrate its general methodological inadequacy). Nevertheless, there are examples of some alternative methodologies that have already been employed which are suggestive of possible strategies for deriving some of the data that are not ascertainable by traditional methodologies. For example, some ethnomethodologists like Alan Blum (1970) have offered phenomenological analyses of language as it is employed within psychiatric settings. Also, Armand Mauss (1975:319-356) has presented a sociohistorical perception of the concept of mental illness as a social movement.* Development of methodologies similar to these will undoubtedly provide some of the necessary research tools.

The propositions are stated very generally and are far from being exhaustive. They are arranged in a manner that tends to move from the broader issues of insanity to those (1971) contention that social problems must be perceived as collective behavior. Blumer's call for a heightened socio-logical sensitivity to the way in which societies respond to their various problems and in doing so largely determine the premises upon which they will be perceived is certainly shown to be relevant in the case of insanity. 
that are more specific.

PROPOSITION I. That sociohistorical analysis will show that the concept of mental illness and the patterns of societal response to it are social constructions deriving from the massive transformation of social relationships that occurred in the shift from feudalism to capitalism.

In the historical period just referred to by this proposition numerous new and different social arrangements emerged. John and Virginia Demos (1973) offer a brilliant analysis of the way in which the concept of adolescence also emerged within this period and Rothman (1971) related the manner in which social changes in this period led to new social responses to old and new problems. The following three corollaries point to some of the factors within developing capitalism that have been instrumental in molding the concept of mental illness and the patterns of social response to it.

COROLLARY IA. That with the development of capitalism the workplace and conditions of living experienced increasing complexity such that many individuals that could have functioned adequately within an agrarian setting found it increasingly difficult to cope with everging labor requirements. 
The many components that undergird successful competition in the labor market are easy to take for granted. When compared with the requirements within feudal society, however, the number of required skills and attributes that go into finding and holding a job in capitalist society are multitudinous. For instance, one must complete enough schooling to at least read and in many cases a prospective employee must possess some minimal academic degree. If one wants to excel in the labor pool he or she must plan sufficiently ahead to acquire the special training or education required by a position that one may not even apply for until several years later such as in any position requiring a graduate degree. One must also be able to arrange for the necessities of everyday life - housing, making up a budget, shopping, transportation, filing income tax returns, filling out all kinds of forms, and so on. The mental skills required in advanced capitalism are many. Increasing complexity of labor and living arrangements may contribute in some ways to the actual incidence of mental disorders by virtue of exacerbating an individual's confusion or perceptual difficulties. More importantly, though, this increasing complexity undoubtedly accounts for extension of the label of mental illness to encompass a wide range of behavioral difficulties raised by a new set of social arrangements. An analysis of labor market changes over the last 200 years and the reported rates of mental illness should show 
a significant relationship between the two; the more complex the labor requirements the higher the reported incidence of mental disorders.

COROLLARY IB. That massive urbanization and increased social and geographical mobility produced a shift in responsibility from the family to society for the care of those experiencing mental difficulties.

At the same time that increasing social complexity broadened the definition of mental deviance, family networks became increasingly fractionalized and less capable of normalizing such behavior. In previous social relationships, such as the extended family rooted in an agrarian society, there existed a communal form of responsibility for those experiencing mental difficulties. Undoubtedly much of what is labeled today as serious mental impairment was normalized within these extended kinship networks. With the advent of capitalism and the emergence of the nuclear family the responsibility for the mentally deviant was socialized, ironically enough, to a level of impersonal and systematized treatment characterized by extensive stigma to the deviants. It is no coincidence that the insane asylum appeared in the same era as did workhouses and prisons, as is shown by Rothman (1971). In fact, as Rosen (1968:277) indicates, many of the mentally disturbed were still located within poor- 
houses, jails, and similar facilities as late as the middle of the nineteenth century, attesting to the fact that these innovations were different components of a common problem: that capitalism effected a massive reordering of social forms as well as a serious disruption of the labor market.

A thorough analysis of documents, records, and personal accounts should show that mental deviance was handled almost entirely within extended kinship networks in pre-capitalistic society. Such sources of data should also reveal a progressive movement to more depersonalized and stigmatizing societal responses to this phenomenon.

One could put forward the argument that the alarming increases in criminality, juvenile delinquency, poverty, and mental disorders that characterized this period are attributable to unemployment, underemployment, and increasing demand for superior mental skills and abilities. There was a total absence of governmental responses to alleviate these difficulties except in the most superficial way.

COROLLARY IC. That the bias within early capitalism toward a "laissez-faire" governmental posture yielded a response directed simply toward getting the socially undesirable people out of the public's view.

The types of societal responses that were made reveal, according to Mauss, that the government was simply doing the least that it could to solve these problems. The incipiency 
of the mental health movement reflected the basic strategy of getting deviants "out of sight and out of mind" - it did not represent a rational response to the latest advances in behavioral science.

While the $18 \mathrm{th}$ century brought with it asylums in Europe and almshouses in America, these developments only seemed to represent moves to get the mentally disordered "off the streets," rather than reflecting significant changes in the attitude toward this form of deviance. These new institutions largely served a custodial function, and were characterized by extremely heterogeneous populations of unfortunates. (Mauss, 1975:337)

Not enough attention has been given to the way in which social responses to mental disorders have operated to mediate the disruptions caused by industrial capitalism.* The mentally disordered are not the only social category that have been generated and stigmatized by the changes that have $\infty-$ curred. According to Goffman we can understand the nature of the social response to mental disorders by viewing it as one among several responses to people who represent problems for capitalistic society.

- we must see the mental hospital in the re-
cent historical context in which it developed, as
one among a network of institutions designed to

* This point is not directly refuted by virtue of similar responses to mental disorders in socialist or communist countries. The predominant modes of conceptualization of mental disorder were developed within capitalistic social structures and contemporary conceptions workdwide (in advanced societies) are still heavily burdened with the past, a point on which we will further elaborate shortly. There is some indication, however, according to sidel (1975), that responses to mental disorders in China operate from very different premises than those of American psychiatric practice, 
provide a residence for various categories of socially troublesome people. These institutions include nursing homes, general hospitals, veteran's homes, jails, geriatrics clinics, homes for the mentally retarded, work farms, orphanages, and oldfolks' hornes. (Goffman, 1973:30)

Sociohistorical analysis of the sort implied by this proposition should yield a picture of continuous obfuscation and mystification of the issues of insanity as the result of using an inadequate model (i.e. the medical model) which has severely restricted the ability to scientifically investigate this area (Mauss, 1975:356). The medical model did provide a handy legitimation for the way in which the mentally deviant were being handled. Like any other sick person the mental deviant was carted off to some appropriate facility at which he or she could be adequately "treated."

Paradoxically the government was being asked to take care of society's growing number of deviants while at the same time there was a strong predilection to adhere to the Spencerian notion that the internal dynamics of capitalism would work themselves out. Critical evaluations of the harmful effects of the status quo simply did not exist. The emerging system was taken for granted and the growing numbers of undesirables simply stored in social warehouses.

for example. Much more investigation of this matter is needed before any conclusions can be drawn. Such investigations of these issues in socialist or communist countries should be sensitive to the ways in which existing responses to mental disorders have emerged historically and how they function at present to bolster the existing political arrangements. 
PROPOSITION II. That traditional psychiatric and psychological practice functions, to a significant degree, as a mechanism of social control.

Given the burgeoning volume of criticism that has been directed toward psychiatric thinking one has to wonder why it has been so resistant to change. One possible answer is that psychiatric practice has provided a needed mechanism for legitimating oppressive responses to those who manage to voice objections, challenges, or queries to the status quo. The dimension of psychiatric practice characterized by social control activities does not typically resemble the form of conspiring actors toward "politically dangerous" persons. Rather it generally appears, at least in a one-dimensional society, almost imperceptably as an ideological or ethical component which thrusts anyone who questions the "givens" of his or her social world into the role of the deviant. The fabric of our society is interwoven with a plethora of institutional, governmental, and bureaucratic edifices that are served by this kind of ideological structure. Comprehensive sociohistorical analysis should uncover a large number of parties and interests that have been, and that now are, served by traditional thought and response to mental disorders and how their power and influence have in turn served to entrench traditional thinking. This calls for Marxian extension of the analyses offered by Rothman (1971), Mauss (1975:ch9), Rosen (1968) and Richard La Piere (1959) in terms of the re- 
lationship between the transformations and interrelatinships within capitalistic society and social construction of the concept of mental illness and the emergence of mental hospitals and psychiatric treatment.

The pervasive use of psychiatric or psychological intervention in our lives can be seen as taking up the slack that exists as the result of the erosion of important "cooling out" mechanisms such as religious instruction which was instrumental in getting people, especially in earlier historical periods, to yield to a variety of oppressive relationships; to accept their "stations in life." When areas in which psychiatry and psychology are employed are investigated they will reveal this function in many different forms. The most overt examples have been identified by Brown (1973:xv).

Industrial psychologists make factory workers more "comfortable," but only in ways to sap their militancy and thus insure corporate profit . . Advertising psychologists aid the corporations on the opposite end by brainwashing people into consuming harmful and/or meaningless products, with the promise of financial and/or sexual success if the correct products are bought. School psychologists push working class children into vocational tracts - . they counsel students against militancy ... [and] report their "antisocial" attitudes to the higher administration. Military psychologists polish the machinery of U.S. imperialism . . . providing "adjustment" for antiwar GI's and counseling bomber pilots so they won't feel guilty about napalming Vietnamese. Behavior modification experts work out tortures to "cure" deviants . . . Social psychologists perform research for counterinsurgency plans at home and abroad . . State hospitals jack people up on thorazine and give electroshock or 10botomies to working class people whose behavior would never be "treated" if they were wealthy. 
The corollaries that follow point out some of the general ways in which traditional psychiatric thought enhances the status quo.

COROLLARY IIA. That the inherent focus in psychiatric theory and treatment upon the individual has blurred vision into the sociological and social psychological dimensions of insanity.

A thoroughgoing survey of the predominant theories and modes of treatment should demonstrate that traditional psychiatric thought excludes all but the most individualistic factors involved in mental disorders. This observation may sound overly simplistic but it must be pointed out that adherence to models and theories that rule out the possibility of the etiological significance of social factors will only generate research and findings that invariably support the theory or model. Truly scientific perspectives seek to find instances or findings that would qualify the theory or model. Self-validating perspectives serve no legitimate scientific purposes although they may often provide valuable commodities to some parties. Again, the propagation of social fictions that are very real in their consequences do not have to be conspiratorial in nature. Psychiatrists are typically exposed to a lengthy experience of secondary socialization in which they inculcate the "truths" and techniques of their profession. They have a definite vested interest in these "truths" in that they help to pre- 
serve the lofty rung in the social ladder upon which the psychiatrist stands. Few choose to criticize their own comfortable profession (seldom is it the king who both perceives the treachery of his reign and rises up in revolt against it). Still some psychiatrists have risen up in rebellion and the number of theorists that point to social factors is growing, albeit very slowly. The vast majority, unfortunately, still respond to their patients as the locus of the causal forces relevant to their current distresses.

COROLLARY IIB. That mental health practitioners typically "treat" their patients by prescribing some form of adjustment to oppressive living conditions.

This corollary could be construed to imply the assumption that all mental disorders are characterized by oppressive living conditions. To overcome this difficulty it would be necessary to evaluate a sample of patients in terms of all potential factors contributing to their present difficulties that could be defined as oppressive. This evaluation would then be compared to the therapists' evaluations to answer two different questions: (1) Did the therapist uncover the oppressive characteristics of the patients' environment if any exist? and, (2) Did the therapist, when aware of oppressive conditions, seek to alter those conditions or to promote adjustment to unaltered conditions? In other words, a therapist may promote adjustment to oppressive con- 
ditions unwittingly be adhering to a line of inquiry that inherently obviates the discovery of such factors by virtue of an exclusive focus on the individual or he may do so by directly facilitating adjustment to known conditions of oppression, whenever oppressive contingencies are relevant to a disorder.

The potential use of residual categories of psychiatric distresses such as schizophrenia or neurosis to mask the existence of oppressive relationships should not be overlooked. A therapist may, for example, decide for a number of possible reasons to avoid confronting a pejorative living condition by using a vague diagnostic label to conveniently "locate" the problem within the patient. For instance, the therapist may engender financial reward, prestige, or some other similar payoff by overlooking the existence of an oppressive relationship.

COROLLARY IIC. That most psychiatric diagnostic categories are social constructions that are devoid of a scientifically skeptical dimension and which are sufficiently vague so as to be of little use in interpreting or treating behavior and which exist, therefore, as self-validating constructs.

We have already referred to the research of caetano (1974), Greenley (1975), Obeysekere (1975), Rosenhan (1975), Siamak (1975), and Temerlin (1975) which have some bearing 
on this issue. These studies are far from exhaustive, however. We need to know more about specific diagnostic categories; where they originated sociohistorically, how they are linked to the medical model, and how they are applied within actual psychiatric settings. This topic is crucial since, according to ethnomethodologists like Blum (1970:38), "mental illness is possible because [people], in very small and ordinary ways, treat certain behavior as 'mentally ill' and collaboratively develop systematic ways of recognizing, categorizing, and acting upon such behavior." That is to say, that particular patterns of social interaction are instrumental in constructing the taken-for-granted reality of mental illness. If we pursue Blum's contention we would systematically observe the way in which categories or descriptions are actually applied to individuals within psychiatric settings.

COROLLARY IID. That psychiatric diagnostic categories are used with regularity to discredit individuals making legitimate claims as to the conditions of their families, school environments, work, government, and other similar entities.

In much previous discussion the nature of discrediting labeling has been explicated. Little research, however, exists to substantiate the claims that have been made. Samples of patients should be evaluated especially in regard to 
the observations that they relate pertaining to their living conditions. Comparisons between the patients' perceptions and the actual nature of the living conditions should evidence a significant proportion of the cases in which the patient is reasonably depicting the existence of oppressive relationships. As the works of Laing, Szasz, and Cooper demonstrate, extreme sensitivity to modes of communication employed and the problems of translation is essential. In cases where the patient is relating oppressive conditions of his or her living situations observations should be made to determine the degree to which the therapist has understood and responded to the patients' claims. Investigations at this point should be especially sensitive to the use of diagnostic labels to discredit the patient. Once again, the act of discrediting labeling need not be conspiratorial in nature, although one should suspect that this is sometimes the case. The absence of inquiries into patients' social environments or the failure to decipher, or even attempt to decipher, their communications grants a large measure of credibility to the labels that are affixed to persons who in very odd ways attempt to relate their painful experiences. The stigma associated with the label still acts to discredit the patient and any past or future claims that are made regarding his or her social environment.

This type of research should move on to cross-cultural investigations. These probes should show a higher incidence 
of discrediting labeling within capitalistic societies or any other type of society characterized by a predominance of sociopsychological manipulation and oppression. These types of sociopsychological manipulations, according to radical analysis, are woven into the very fabric of capitalist societies.

PROPOSITION III. That oppressive agencies of socialization are instrumental in producing and/or exacerbating many mental disorders.

Our analys is has recounted the ways in which the various agencies of socialization within capitalistic society are often engaged in the oppressive transmission of a conception of reality that is presented as inevitable and infallible. The very fact that individuals are socialized to accept the social constructions of reality of their families and social groups as inevitable can result in serious distortion of their perceptual abilities. If one should suffer from the nature of oppressive living conditions his or her ability to identify the source of suffering and successfully communicate that observation to others is often severely restricted. For the individual suffering from some other source of debilitation, such as endocrinic, genetic, or neurological defects, this type of socialization experience operates to intensify the person's confusion or disorientation. 
Extensions of the research that has inspected various dimensions of the authoritarian personality should further demonstrate the perceptual distortions deriving from authoritarian socialization practices.

COROLLARY IIIA. That early oppression in the family restricts development of the self (in a Meadian sense) and other aspects of genuine autonomy in the child.

The case studies related by Laing and cooper point out the likely relationship between oppressive family structures and the incidence of mental distress in those upon whom such oppression is focused. Much more investigation of the messages offered by the mentally disturbed is needed to explicate the relationship between oppressive socialization and the development of individual autonomy that is demonstrated in intrapersonal communication between the "I" and the "me." Complete development of the self allows one to fully distinquish between acts and attitudes that are initiated by one's self and those initiated by others. A youngster that has been oppressively trained is severely restricted from either initiating genuinely autonomous actions or even perceiving that his or her actions derive from parental training.

Also samples of mental patients should be inspected in terms of the incidence of relevant oppressive family struc- 
tures. It is possible that different forms of family oppression are linked to specific types of mental difficulties. Unfortunately, little work has been done in this area. Some studies investigating double-bind family structures, however, touch on this area, especially in pointing to the effects of overly dominant mothers upon children. A more explicit emphasis upon the role of oppression in these studies of family structures should provide some of the answers to the questions that have been raised here.

COROLLARY IIIB. That early experiences of oppression severely incapacitate a person's ability to identify oppressive contingencies and to relate those contingencies to others.

An oppressive parent may refuse to allow a child the possibility of referring to him or her with any negative symbols. The youngster therefore has access only to positive symbols when referring to the parent. Thus, it becomes impossible to locate the source of one's suffering or pain within one's parent. Schatzman points out the way in which Schreber's father accomplished this withholding of negative symbols for himself from his son. Even many years later Schreber was still unable to link negative symbols with his father. Research should be directed toward the symbolic capabilities of mental patients in reference to parents or other significant persons. 
The possibility also exists that a range of emotions that for most people have been ascribed comfortable symbolic status have been denied symbolic referents for those suffering from mental distress. The observations made by Szasz certainly point to the very real difficulties that sufferers of mental distress have in communicating their feelings. Obviously, much more research into these areas is needed.

COROLLARY IIIC. That oppressive responses by mental health professionals further mystify the relationships within which those suffering from sociopsychological distress find themselves.

If, as we have contended, the mentally distressed individual experiences severe perceptual and communicational distortion and confusion then further oppressive responses from therapists will only intensify the problem. Thrusting the mental patient into a situation in which he or she is given a variety of alleged internal constructs (e.g. anal fixation, latent homosexual love, Oedipal conflicts, etc.) merely serves to compound the confusion that is experienced. Attention is shifted away from external empirical factors to internal abstractions. The patient is forced to think and communicate in this mode by virtue of the fact that this is the mode established by the therapist who, by definition, stands in a superordinate position to the patient within the therapeutic setting. The patient may also feel compelled to 
communicate within the confines of this mode for fear of losing what may be his or her only source of attention and response to the experienced problems. For the patient this presents a dual problem: (1) the objective living conditions that are instrumental in the present difficulty are not being dealt with; and, (2) the patient has now been labeled and stigmatized in such a manner that complaints or rejection of the dominant therapeutic mode would simply lend credence to the label that has been used. A systematic investigation of the therapeutic milieu through a series of participant observational studies should help to illuminate these processes.

PROPOSITION IV. That, when the individual challenges accepted socially constructed reality, a number of intrapersonal processes are set in motion which generate, to varying degrees, a variety of sociopsychological distresses.

The preceding propositions and corollaries address the way in which agencies of socialization and social control interact to entrench conventional conceptions of reality in the minds of individuals. When, for whatever reason, one challenges these conventional conceptions a number of internal and external events occur which, at best, will yield some rather unpleasant and stressful experiences and which, at worst, will lead to complete loss of contact with one's 
fellows and the reality shared therewith.

COROLLARY IVA. That one consequence of challenging generally accepted notions of social reality is the emergence of experiences of confusion, doubt, or guilt that, if severe enough, will eventuate in serious mental impairment.

In the process of terminating one's allegiance to a reality that has been internalized over a lengthy period of time one may be left in a state of limbo or seclusion from a solid social base of reality. The bonafide revolutionary will be among those that will undoubtedly suffer the least in such situations in that he or she is typically shedding one socially based perception of reality for one that is unconventional, radical, or unpopular but which still has some social foundation. The extreme comradery that of ten characterizes revolutionary groups undoubtedly reflects the need for a socially shareable alternative reality for such people. The atheist in a predominantly religious culture may have more difficulty in finding a shareable conceptual alternative. In both cases there is the liklihood that numerous experiences of confusion, doubt, and guilt will creep into the consciousness of the challengers. The youngster rejecting the reality imposed by the family will experience even more difficulty. Who is there to share his or her deviant perception of the family situation? This person 
may very well be locked into intrapersonal communication regarding the family yielding increasing reliance upon idiosyncratic symbols which intensify the communicational problems as they spill over into interpersonal interaction, in which contexts they stimulate negative social reactions. These aversive social experiences will in turn engender greater reliance upon idiosyncratic intrapersonal communication. The point may come, as is suggested in the observations made by Laing, Cooper, Schatzman, and others, where the distressed individual may no longer be able to distinguish between the self and others or between intrapersonal and interpersonal communication.

COROLLARY IVB. That a second consequence of challenging conventional conceptions of reality is an ensuing process of social reactions that tend to intensify the feelings of confusion, doubt, and guilt.

The typical response to unconventional or deviant conceptions of reality is one of intolerance, ridicule, and castigation. Ranging from a raised eyebrow to some type of physical punishment, these responses tend to elicit feelings of hesitancy and anxiety. If one persists, a process of systematic exclusion from further interaction may follow which contributes to the shrinkage of one's social base for sharing reality. As Lemert has so perceptively observed, the "dynamics of exclusion" serve to amplify the problems ex- 
perienced by the deviant and so grant credence to the contention that he or she is increasingly "psychotic" or "emotionally disturbed."

The psychiatric labels that are often applied may evoke such morbid fear in the mind of the labeled person that he or she is disoriented to the point of fulfilling the most extreme symptoms that are implied by the particular label. The child that goes against strong parental directives can also experience the debilitating effects of intense fear. For example, the youngster who masturbates after being continually warned that it will cause "madness" may experience a degree of anxiety sufficient to precipitate behavior that is supposedly symptomatic of that "madness."

It is easy to overstate the case embodied in the last two corollaries; but this shouldn't effect a barrier to the kind of investigations that would shed light on these issues. Admittedly, developing appropriate methods of inquiry into these questions would be difficult. One could, however, observe and interview subjects displaying various types and degrees of deviant conceptual constructs in a number of natural and experimental settings to determine some of the intra- and interpersonal processes involved.

The foregoing set of propositions and corollaries are offered as a beginning point for research that would move from a radical sociology of knowledge perspective on the issue of insanity. To this point investigation into these 
96

areas has been minimal and much of the argument is more thetorical than demonstrably empirical. Often the findings that do exist are the result of dubious techniques such as case studies. What is needed is a rigorous and comprehensive research effort begining with these propositions or similarly constructed statements that clarify this position both in terms of prediction and those conditions under which it should hold. 
CHAPTER VI

CONCLUSIONS

In our sociological excursus into the ambiguous world of insanity we have witnessed how that psychiatry and the concept of "mental illness" have evolved as a historical response of society to an enduring social problem. The sociology of knowledge, when modified to incorporate the distribution of power in social relationships, proves to be an effective analytic tool by which to chip away the heavy scales of mystification and reification that have enshrouded both the past and contemporaneous role of knowledge and consciousness in the societal response to insanity. A radical sociology of knowledge provides the necessary link between phenomenological and dialectical approaches that enables us to more completely conceptualize the social construction of reality in history. The treatment of this point in this paper has largely been suggestive; this formulation is subject to considerable refinement and clarification.

In terms of the "antipsychiatry" literature this framework provides the crucial focus upon the relationship between individual crises in knowledge and the nature of knowledge in its everyday life contexts inasmuch as it is sensitive to the dialectical and phenomenological relationship between 
individual and society. Our analysis has suggested the advantages of a radical sociology of knowledge over a radical psychology as an interpretive framework for the general critique of the mental health establishment found in the "antipsychiatry" literature. A radical psychology will do justice to only half of the dialectical relationship between man and society. This is not to invalidate some of the intermediary findings that such a perspective may reveal. Certainly the role of biopsychological factors in various aspects of defective socialization needs much further clarification; but the "antipsychiatry movement" calls for a much more comprehensive analysis of these issues. The very sociohistorical context of the "movement" is rooted in a general critique of captialism that gained momentum in the 1960 's. This factor linked with the disappointing failures of traditional psychiatric and psychological approaches regarding insanity has continually pointed toward the role of external factors. This is a call for the holistic analysis of a radical sociology of knowledge which, unlike traditional psychological and sociological perspectives, treats both social structure and individual consciousness as parts of the same process. An added advantage of this framework is its inherent relativistic nature which should make it less susceptable to the crystallization or reification that had been so pervasive in analyses of the phenomenon of insanity.

Another advantage is the fact that a radical sociology 
of knowledge carries with it a sociopsychological perspective (i.e. Meadian social psychology) that has become increasingly acceptable to Marxists. This nascent perspective refuses to conceive of the individual qua individual; rather it promotes an image of man as a social being whose consciousness is a social product. The suggestions regarding the incorporation of the Meadian perspective into radical analysis needs to be inspected in much greater detail than we have been able to do here.

We have also suggested what is felt to be a coherent method of incorporating the labeling perspective within radical sociological theory. This involves conceptualizing the process of labeling as an aspect of social control based upon the discrediting of deviants and their insights, observations, and complaints, in efforts to buttress the status quo. Addition of the factors of differential power distribution to traditional labeling arguments has enabled us to discuss everyday life in terms of its political dimensions sensitizing us to the existence of the oppressive use of labeling at this level of social life. We have been able to discuss this oppression as the indirect effect of the class struggle in western society, thus avoiding the pitfalls of mechanistic Marxism. The point to be stressed is that those possessing positions of relative power tend to utilize that power to reify the status quo in their own interests. Our investigation has revealed a paucity of research 
into many important issues of insanity. Much of the research that has been carried out moves from self-validating premises of traditional psychiatric approaches. In response we have developed a set of propositions that, if tested, would lay the empirical groundwork for a radical investigation of "mental illness." The propositional model is a mere skeletal configuration of what wholesale investigation of these issues would involve. Thus, there are many questions that have gone unaddressed in this inquiry.

For example, we have dealt with some specific "mental disorders" and suggested some ways to analyze the role of oppression in their etiology and remediation. This area needs much more exploration and clarification. We failed to deal with such psychiatric categories as neurosis, alcoholism, or manic-depressive psychosis. If, as we have suggested, the oppressed are calling for help via a "mental disorder" why is it that a specific disorder is chosen over others? The psychiatric categories of schizophrenia, paranoia, and hysteria continually emerge in the "antipsychiatry" literature. Is it possible that these are the only categories in which oppression is implicated as a causal force? What is the role of oppression upon different processes of socialization that might lead to particular types of behavioral responses? These are some of the questions that arise from our investigation that when addressed should further clarify the role of oppression in the etiology of insanity. 
In terms of treatment, a radical sociology of knowledge implies a dual strategy of working with individuals to impart to them an understanding of the inherent problems of socially constructed reality and to help them modify the oppressive contingencies within their own environments. This approach suggests that "crazy" communications be inspected in terms of complaint and suffering rather than disorder and illness. A question for the future is an unenviable analysis of the family; its oppressive characteristics and the various alternatives to it. The sticky issue of intervention into families and the legal rights of parents will become paramount in this discussion.

It is certain that the effects of isolation and dehumanization characteristic of mental hospitals and psychiatric treatment are decidedly pejorative according to this framework; social reality is best maintained through language, conversation, and interaction; not warehousing.

Though the questions that have been raised by this investigation far outweigh the answers one has to feel confident that at least some of the dimensions of insanity can be fruitfully conceptualized within a radical sociology of knowledge. It certainly represents a marked improvement over traditional responses to insanity and yields a coherent mode for conceptualization of the "antipsychiatry" insights. We should repeat the observation that a radical analysis of insanity within Western society such as that offered 
in this paper should in no way be construed to mean that insanity is caused by capitalism per se. Obviously insanity exists in all known types of society, both primitive and socialist. Cross-societal research into insanity investigating the role of oppression should help us to further understand the operation of knowledge as it is dialectically constructed and as it relates to the problems of consciousness suggested by Marx and others. 
REFERENCES CITED

Angel, Jerome (ed.)

1971 The Radical Therapist. New York: Ballantine Books.

Artaud, Antonin

1965 In J. Hirchman (ed.), Artaud Anthology. San Francisco: City Lights.

Bastide, Roger

1972 The Sociology of Mental Disorder. Translated by Jean McNeil. New York: David McKay.

Bateson, Gregory, et al.

1956 "Toward a Theory of Schizophrenia." Behavioral Science 1:251-264.

Berger, John

1974 The Look of Things. New York: Viking.

Berger, Peter I.

1969 Marxism and Sociology: Views From Eastern Europe. New York: Appleton, Century, Crofts.

Berger, Peter L. and Luckmann, Thomas

1967 The Social Construction of Reality: A Treatise in the Sociology of knowledge. Garden City, N.J.: Doubleday.

Berger, Peter L. and Pullberg, Stanley

1965 "Reification and the Sociological Critique of Consciousness." History and Theory 4(2): 196-211.

Blum, Alan

1970 "The Sociology of Mental Illness." Pp.31-60 in Jack Douglas (ed.), Deviance and Respectability: The Social Construction of Moral Meaning. New York: Basic Books.

Bl umer, Herbert

1971 "Social Problems as Collective Behavior." Social Problems 18(3) 298-306.

Bolton, Charles D.

"Outline of a Symbolic Interactionist Frame of Reference." (Unpublished manuscript). 
Brooks, Keith

1973 "Freudianism is Not a Basis for a Marxist Psychology." Pp. 315-374 in Phil Brown (ed.), Radical Psychology. New York: Harper and Row.

Brown, Phil (ed.)

1973 Radical Psychology. New York: Harper and Row.

Caetano, Donald F.

1974 "Labeling Theory and the Presumption of Illness: An Experimental Design." J. of Health and Social Behavior 15(3) 253-260.

Cooper, David

1973a "Violence and Psychiatry." Pp.128-155 in Phil Brown (ed.), Radical Pshchology. New York: Harper and Row.

1973b "Being Born Into a Family." Pp.156-173 in Phil Brown (ed.), Radical Psychology.

Demos, John and Demos, Virginia

1973 "Adolescence in Historical Perspective." Pp.209221 in Michael Gordon (ed.), The American Family in Social-Historical Perspective. New York: St. Martin's.

Dingwall, R.W.H.

1975 "Ethnomethodology and Marxism." Sociology 9(3): 495-496.

Erikson, Kai T.

1967 "Notes on the Sociology of Deviance." Pp.9-21 in Howard S. Becker (ed.), The Other Side. New York: Free Press.

Freud, Sigmund

1893 "Charcot." Pp.9-23 in Collected Papers, Vol.I. London: Hogarith Press.

Garfinkel, Harold

1956 "Conditions of Successful Degradation Ceremonies," American Journal of Sociology, 61:420-424.

Gibbons, Don C.

1976 Delinquent Behavior. Englewood Cliffs, N.J.: Prentice-Hall.

Gibbons, Don C. and Jones, Joseph J.

1975 The Study of Deviance: Perspectives and Problems. Englewood Cliffs, N.J.: Prentice-Hall. 
Glenn, Michael

1971 Introduction to Jerome Angel (ed.), The Radical Therapist. New York: Ballantine Books.

Goffman, Erving

1961 Asylums. Garden City, New York: Anchor Books.

1973 "The Medical Model and Mental Hospitalization." Pp. 25-45 in Phil Brown (ed.), Radical Psychology. New York: Harper and Row.

Gove, Walter F.

1975 "Labelling and Mental Illness: A Critique." Pp.3581 in W.F.Gove (ed.), The Labelling of Deviance: Evaluating a Perspective. New York: Wiley.

Greenley, James R.

1975 "Alternative Views of the Psychiatrist's Role." Pp.34-46 in T.J.Scheff (ed.), Labeling Madness. Englewood Cliffs, N.J.: Prentice-Hall.

Halleck, Seymour L.

1971 The Politics of Therapy. New York: Science House.

Hansen, Donald A.

1976 An Invitation to Critical Sociology. New York: Free Press.

Hollingshead, August and Redlich, Frederick

1958 Social Class and Mental Illness: A Community Study. New York: John Wiley.

Kersey, Ken

1962 One Flew Over the Cuckoo's Nest. New York: Viking.

Kozol, Jonathan

1976 "Death at an Early Age." Pp.384-389 in J.H.Skolnick and E.Currie (ed.), Crisis in American Institutions. Boston: Little Brown.

Kupers, Terry A.

1976 "Schizophrenia and Reification." Socialist Revolution, 6(3):105-124.

La Piere, Richard

1959 The Freudian Ethic. New York: Duell, Sloan, and Pearce.

Laing, R. D.

1960 The divided Self. London: Travistock. 
1969 "The Obvious." In David Cooper (ed.), To Free a Generation. New York; Collier.

1973a "The Ghost of the Weed Garden: A study of a Chronic Schizophrenic." Pp.68-108 in Phil Brown (ed.), Radical Psychology, New York: Harper and Row.

1973b "The Mystification of Experience." Pp.109-127 in Phil Brown (ed.), Radical Psychology.

Lauter, Paul and Howe, Florence

1976 "How the School System is Rigged for Failure." Pp. 390-408 in J.H.Skolnick and E. Currie (eds.), Crisis in American Institutions. Boston: Little Brown.

Lemert, Edwin M.

1972 "Paranoia and the Dynamics of Exclusion." Pp.246264 in Lemert (ed.), Human Deviance, Social Problems, and Social Control. Englewood Cliffs, N.J.: Prentice-Hall

Lich tman, Richard

1975 "Marx's Theory of Ideology." Sacialist Revolution (May) : 45-76.

Lucács, Georg

1971 History and Class Consciousness. London: Merlin Press.

Madison, Simon

1973 "Mindless Militants? Psychiatry and the University." Pp.111-135 in Ian and Laurie Taylor (ed.), Politics and Deviance. Baltimore: Penguin.

Marcuse, Herbert

1964 One-Dimensional Man. Boston: Beacon Press.

Marx, Karl

1964 In T.B.Bottomore and Maximilien Rubel, Karl Marx, Selected Writings in Sociology and Social Philosophy. New York: McGraw-Hill.

$1967 a$ "The German Ideology." In Lloyd Easton and kurt Guddat (eds.), Writings of the Young Marx on Philosophy and Science. New York.

1967b Capital, Vol.I. New York: International Publishers. Mauss, Armand L.

1975 Social Problems as Social Movements. New York: Lippincott. 
Mitchell, Juliet

1976 "Woman's Estate." Pp.198-215 in J.K.Skolnick and E. Currie (eds.), Crisis in American Institution. Boston: Little Brown.

Movahedi, Siamak

1975 "Loading the Dice in Favor of Madness." J. of Health and Social Behavior 16(2)192-197.

Obeysekere, Gananath

1975 "The Idiom of Demonic Possession: A Case Study." Pp.135-151 in T.J.Scheff (ed.), Labeling Madness. Englewood Cliffs, N.J.: Prentice-Hall.

Ropers, Richard

1973 "Mead, Marx, and Social Psychology." Catalyst 7: 42-61.

Rosen, George

1968 Madness in Society. Chicago: U. of Chicago Press.

Rosenhan, David L.

1975 "On being Sane in Insane Places." Pp.54-74 in T.J. Scheff (ed.), Labeling Madness. Englewood Cliffs, N.J.: Prentice-Hall.

Rothman, David J.

1971 The Discovery of the Asylum. Boston: Little, Brown, and $\mathrm{Co}$.

Schaff, Adam

1970 Marxism and the Human Individual. New York: MCGrawHall.

Schatzman, Morton

1975 "Paranoia or Persecution: The Case of Schreber." Pp.90-119 in T.J.Scheff (ed.), Labeling Madness. Englewood Cliffs, N.J.: Prentice-Hall.

Scheff, Thomas $J$.

1975a Labeling Madness. Englewood Cliffsn N.J.: PrenticeHall.

1975b "Schizophrenia as Ideology." Pp.5-12 in T.J.Scheff (ed.), Labeling Madness.

1975c "On Reason and Sanity: Some Political Implications of Psychiatric Though." Pp.12-20 in T.J.Scheff (ed.), Labeling Madness.

1975d "The Labeling Theory of Mental Illness." Pp.21-34 in T.J.Scheff (ed.), Labeling Madness. 
1975e "Labeling, Emotion, and Individual Change." Pp.7589 in T.J.Scheff (ed.), Labeling Madness.

Schreber, D.G.M.

1858 Kallipadie oder Erziehung zur Schonheit durch Naturgetrue and Gleichmassige Forderung Normaler Korperbilding (Education Towards Beauty by Natural and Balanced Furtherance of Normal Body Growth). Fleischer: Leipzig

Schreber, Daniel P.

1955 Memoirs of My Nervous Illness. (1903) Translated and edited by I.MacAlpine and R.A.Hunter. London: Dawson and Son.

Schroyer, Trent

1975 The Critique of Domination. Boston: Beacon Press.

Shur, Edwin M.

1973 Radical Non-intervention: Rethinking the Delinquency Problem. Englewood Cliffs, N.J.: PrenticeHall.

Sidel, Ruth

1975 "Mental Diseases in China and Their Treatment." Pp.119-134 in T.J.Scheff (ed.), Labeling Madness. Englewood Cliffs, N.J.: Prentice-Hall.

Szasz, Thomas $S$.

1974 The Myth of Mental Illness. New York: Harper and Row.

Temerlin, Maurice K.

1975 "Suggestion Effects in Psychiatric Diagnosis." Pp.46-54 in T.J.Scheff (ed.), Labeling Madness.

ardell, Mark L.

1975 "Toward a Joing of Marx and Mead." Paper presented at Annual Meeting of the Midwest Sociological Society.

Weinberg, S. Kirson

1968 "The Commitment of Patients to the Mental Hospital." Pp.182-183 in S. Kirson Weinbert (ed.), The Sociology of Mental Disorders. Chicago: Aldine.

Willer, Judith

1971 The Social Determination of Knowledge. Englewood Cliffs, N.J.: Prentice-Hall. 